\title{
Bidding at Sequential First-Price Auctions with(out) Supply Uncertainty: A Laboratory Analysis ${ }^{\dagger}$
}

\author{
Tibor Neugebauer \\ Department of Economics, \\ University of Hannover, \\ D-30167, Germany
}

\author{
Paul Pezanis-Christou \\ Institut d'Anàlisi Econòmica (CSIC) \\ Campus UAB, \\ Bellaterra 08193, Barcelona, Spain
}

February 7, 2003

\begin{abstract}
We report on a series of experiments that test the effects of an uncertain supply on the formation of bids and prices in sequential first-price auctions with private-independent values and unit-demands. Supply is assumed uncertain when buyers do not know the exact number of units to be sold (i.e., the length of the sequence). Although we observe a non-monotone behavior when supply is certain and an important overbidding, the data qualitatively support our price trend predictions and the risk neutral Nash equilibrium model of bidding for the last stage of a sequence, whether supply is certain or not. Our study shows that behavior in these markets changes significantly with the presence of an uncertain supply, and that it can be explained by assuming that bidders formulate pessimistic beliefs about the occurrence of another stage.
\end{abstract}

Keywords: sequential first-price auctions, independent private values, unit-demand, supply uncertainty, bidding behavior, price trends, experimental economics

\section{J.E.L. Classification Numbers: D44, C9}

\footnotetext{
${ }^{\dagger}$ We thank Roberto Burguet, Werner Güth, Tanga McDaniel and seminar participants at the Economic Science Association, the Econometric Society European Meetings, the Max Planck Institute (Jena), and the universities of Pompeu Fabra and Tilburg for helpful comments. We are also indebted to Enrique Fatás and Abdolkarim Sadrieh for their generous help with the conduct and the programming of the experiments. Financial support from the University of Valencia (project GV98_08/2960) and from a EU-TMR ENDEAR Network Grant (FMRX-CT98-0238) is gratefully acknowledged.

Email Addresses: Neugebaeur: t.neugebauer@mbox.vwl.uni-hannover.de ; Pezanis-Christou: ppc@iae.csic.es
} 
In his survey of various real-world auction markets, Cassady (1967) reports the existence of auctions where sellers withhold from buyers any information concerning the amount of supply available for sale. Such practice has been observed in various fish markets of France and Spain, and in some flower markets in the Netherlands. In the fish market of Sète (France) for example, the auction starts when the first trawler disembarks. The merchandise is offered in lots of a certain number of kilos of a given species of fish. Each of these lots is then carried on a moving belt from the storeroom to the buyers and additional supply is displayed, in the same way, according to the boats' order of arrival. Buyers can thus only see the offerings as the auctioneer starts the auction, without further information about the day's supply. Another example where this feature applies are internet auctions since bidders in these auctions typically do not have information about future supplies.

In this paper we study the effects of an uncertain supply on the formation of bids and prices in sequential first-price auctions and we test our theoretical predictions with experimental data. We consider the benchmark model for sequential auctions of Milgrom and Weber (1982) that assumes private-independent values and unit-demands. A well-known result of this model is that if $k$ identical units are sold one after the other to $n$ risk neutral bidders, then the resulting series of expected prices is constant if buyers are certain about $k$. A large body of subsequent research on sequential auctions stems from Ashenfelter's (1989) observation of a 'declining price anomaly' at wine auctions, and has characterized conditions on buyers' preferences (e.g., von der Fehr, 1994, Engelbrecht-Wiggans, 1994, Bernhardt and Scoones, 1994, Ginsburgh, 1998) or on market specifics to observe deviations from the Lawof-One-Price (e.g., Ashenfelter and Genesove, 1990, Black and De Meza, 1992, Menezes, 1993, Gale and Hausch, 1994, Beggs and Graddy, 1995, Gandal, 1998, Katzman, 1999). McAfee and Vincent (1993) show that for the benchmark model of Milgrom and Weber (1982), expected prices would decline and an efficient allocation of goods can be guaranteed only if buyers display non-decreasing absolute risk averse (NDARA) preferences, which is not considered to be a plausible assumption for real-world behavior. If buyers' preferences are characterized by the more realistic assumption of decreasing absolute risk averse (DARA) preferences then no increasing equilibrium strategies can be defined, so that the allocation of goods can be inefficient and expected prices may not decline. Laffont, Loisel and Robert (1998) show that the price trend predictions of the benchmark model with NDARA buyers extend to the case where they can decide not to bid in stage $t<k$ and bid again in stage $t+1$. 
We study the effects of an uncertain supply by assuming that the maximum number of items sold is $k$ but that in each stage $1<t<k$, the probability that there will be another stage $t+1$ is equal to $\delta<1$. We determine the symmetric pure Risk Neutral Nash Equilibrium (hereafter, RNNE) bidding strategies and show that the greater the uncertainty (i.e., the smaller $\delta$ ), the more the expected prices decline. The intuition underlying this result is that the RNNE bidding strategy for stage $t$ is the average of the remaining $k-t+1$ RNNE bids assuming $\delta=1$, weighted by the probabilities that there will be $0,1,2, \ldots,(k-t)$ more units for sale. To this extent, the analysis of supply uncertainty in a model $a ̀$ la Milgrom and Weber (1982) provides clear predictions not only on bids and prices but also on their respective stage-to-stage patterns. Since the effect of such an uncertainty on bids and prices is equivalent to assuming that bidders discount their future profits, our predictions hold for sequences of auctions in which bidders are impatient to acquire their units. This framework is also simple enough to allow for extensions regarding the seller's optimal policy about the release or withholding of information about supply (Pezanis-Christou, 1996) or to check the effects of the arrival of new information about supply during the course of a sequence (Jeitschko, 1999). Burguet and Sákovicz (1997) consider a similar framework for second-price auctions in which buyers are also uncertain about total demand, which is technically equivalent to assuming the existence of a buyer's option as in Black and De Meza (1992).

We choose to limit our study to sequences of first-price auctions because most markets in which supply is uncertain are organized in sequences of descending-price auctions, which are usually assumed to be strategically equivalent to first-price auctions (e.g., Laffont, Loisel and Robert, 1998). ${ }^{1}$ Also, the first-price auction format allows a better assessment of bidding behavior than the Dutch format since it generates bid and price data whereas the Dutch format generates only price data. The effect of an uncertain supply on bidders' equilibrium behavior would also be palatable in more sophisticated settings that involve multi-unit demands and affiliated values, as in Hausch $(1986,1988)$, since bidders would still have to account for the likelihood of future stages in their early bids. However, its effect on price trends is modeldependent. In the unit-demand framework of Milgrom and Weber (1982), the impact of supply uncertainty on price trends when bidders have affiliated values would depend on the

\footnotetext{
${ }^{1}$ This is the case only if the winning bid is announced after each auction stage. For the single-unit case, Cox, Roberson and Smith (1982) report experimental evidence that the strategic equivalence of these two formats does not hold in the laboratory because first-price auctions generate higher revenues than Dutch auctions. However, Katok and Kwasnica (2002) show that the revenue ranking of these two formats depends on the speed at which the selling price decreases in Dutch auctions so that the strategic equivalence of the two formats, which implies revenue equivalence, would hold only for specific clock speeds.
} 
potential for the winner's curse (which decreases as the sequence unravels so that when $\delta=1$ price trends are increasing) and the likelihood of future supply (which induces bidders to weigh more early stages). As laboratory studies of bidding behavior in sequential auctions are still scarce, our experiments aim at analyzing the effects of an uncertain supply in the simplest multi-unit version of the first-price auction mechanism, for which behavior is already well documented in the experimental literature (Kagel, Harstad and Levin, 1987, Cox, Smith and Walker, 1988, Chen and Plott, 1998, Goeree, Holt and Palfrey, 2002; see Kagel, 1995, for a survey of the literature).

Frahm and Schrader (1970) report a first experimental examination of price convergence in sequential English and Dutch auction mechanisms when bidders compete with entire demand schedules and are uncertain about supply. These experiments, which were not aimed at studying real-world auction mechanisms or the possible effects of supply uncertainty on bids and prices, provide some evidence that price volatility is more important when an English auction is used. Burns (1985) compares the bidding behavior of professional bidders on wool markets to the one of students in sequential English auction experiments with multiunit demands. These experiments suggest that prices decline less severely in sequences involving students than in sequences involving professional bidders because the latter use heuristics ("reflex actions", Burns, p.151) which they follow in the real-world wool market. Pitchik and Schotter (1988) analyze the effect of budget constraints on behavior in two-period two-bidder auction experiments with multi-unit demands and perfect information and find that the observed prices support well a trembling-hand perfect equilibrium argument. Our study relates most to the one of Keser and Olson (1996) on sequential first-price auction experiments with supply certainty. They report negative prices trends and a significant overbidding (i.e., bidding above the RNNE prediction) so that both the bid and the price predictions of Milgrom and Weber (1982) would not be supported by data. Our experiments, which involved longer series of repetitions than Keser and Olson (1996), suggest instead that some of these predictions hold qualitatively and that some even hold quantitatively.

We considered three treatments: two with supply uncertainty $(\delta=0.6$ and $\delta=0.8)$ and one with supply certainty $(\delta=1)$. In each treatment, subjects played in 100 sequences of firstprice auctions that involved eight bidders. In each round of the uncertainty treatments, a maximum of four units of a fictitious good were sequentially put up for sale whereas in the certainty treatment there always were four units for sale. 
Our main results can be summarized as follows. First, despite a significant overbidding for the first three units in all treatments, we could not reject the RNNE model of bidding for the fourth unit in all treatments. Second, most stage-to-stage patterns of bids are consistent with the RNNE predictions in the aggregate. Third, consecutive average prices are constant when supply is certain and they are declining when supply is uncertain. Fourth, average prices decline more severely as $\delta$ decreases, and the average price of the last unit is the same across treatments, as predicted in the RNNE.

These results are interesting in the light of subjects' behavior. Overbidding in first-price auction experiments is a commonly observed pattern and has usually been attributed to the presence of constant relative risk aversion (Cox et al., 1982, 1988; see also Kagel, 1995) However for this sequential framework, monotone increasing equilibrium strategies for constant relative risk averse (DARA) bidders do not exist (cf. McAfee and Vincent, 1993). Yet, the outcomes of spline regressions indicate that bidders use monotone increasing strategies, but only when supply is uncertain. Therefore, overbidding in these treatments would be consistent with the RNNE predictions if bidders were assumed to formulate pessimistic beliefs $\delta^{*}<\delta$ about the occurrence of another stage. We find that this behavioral hypothesis fits well subjects' bids in these treatments. However, when supply is certain, subjects bid as if they "wait-and-see" the outcome of this first stage whenever they receive a high value, and they more aggressively upon receiving a low value. Such an ex-post asymmetric behavior is not supported by the model's predictions and shows that behavior in these auctions is very sensitive to the presence or not of an uncertain supply.

The next section provides the theoretical framework and the predictions to be tested. Section 2 describes the experimental procedure. Results are reported in Section 3, and Section 4 concludes the paper.

\section{Theoretical framework}

We assume that $n>2$ risk-neutral buyers attend a market in which $1<k<n$ homogeneous units are to be sold one after the other, in $k$ auction stages. At the end of each stage, one unit is awarded to the buyer who submitted the highest bid. Each buyer $i$ has private information concerning his own resale value $x_{i}$ for the item to be sold. All resale values are independently drawn (with replacement) from a given probability distribution function $F$, which has a continuous density $f$ defined on $[0 ;+\infty)$. Buyers have unit demands: each of them desires only one unit of the items offered for sale. Uncertainty about supply is introduced by 
assuming that there is a maximum possible number $k$ of items to be auctioned and that after each auction stage $t<k$, one more sale may occur with probability $\delta \in(0,1)$. We assume that $n, k, \delta$ and $F$ are common knowledge to all buyers and that only the winning bid is revealed at the end of each auction stage. As the results refer to order statistics, we define the random variable $X_{(i)}$ (and its realization $x_{(i)}$ ) as the $i^{\text {th }}$ highest of a sample of $n$ identical and independent draws from $F$ so that $X_{(1)} \geq X_{(2)} \geq \ldots \geq X_{(n)}$.

In a first-price auction, the item is awarded to the highest bidder for a price equal to his/her bid. If there is only one item to be sold, Vickrey (1961) showed that a symmetric equilibrium strategy would be for a buyer to submit a bid equal to the expectation of the second highest value given that he/she is supposed to have the highest one. That is, $b(x)=E\left\{X_{(2)} \mid X_{(1)}=x\right\}$. For $k>1$ and $\delta=1$, Milgrom and Weber (1982) showed that in a sequence of $k$ stages a bidder's symmetric equilibrium strategy is to submit in stage $t \leq k$ a bid equal to the expectation of the $(k+1)^{\text {th }}$ highest value given that his/her valuation is the $t^{t h}$ highest (i.e., $\left.b_{t}(x)=E\left\{X_{(k+1)} \mid X_{(t)}=x\right\}\right)$. The following proposition generalizes this result to cases where $\delta \in(0 ; 1]$.

Proposition 1: Let $k$ be the maximum possible number of items to be sold, and define $\delta$ as the probability that one more auction stage will occur. For the sequential first-price sealed bid auction with unit-demands and private-independent values there exist a unique $k$-tuple $\left(b_{1}, b_{2}, . ., b_{k}\right)$ of symmetric increasing equilibrium bidding strategies whose components are defined as follows:

$$
\begin{aligned}
b_{k-l}(x)= & \delta^{l} \cdot E\left\{X_{(k+1)} \mid X_{(k-l)}=x\right\}+ \\
& \sum_{i=0}^{l-1} \delta^{i}(1-\delta) \cdot E\left\{X_{(k-l+i+1)} \mid X_{(k-l)}=x\right\}, \quad \text { for } l=1, . ., k-1
\end{aligned}
$$

and

$$
b_{k}(x)=E\left\{X_{(k+1)} \mid X_{(k)}=x\right\}
$$

Proof: See Appendix 2.

It appears from Proposition 1 that for $\delta \in(0 ; 1)$ and for $t<k$, the equilibrium bidding strategy is a pure strategy that evens out all possible outcomes: at stage $t$, the equilibrium 
strategy is an average of equilibrium strategies of the $k-t+1$ remaining subgames when $\delta=1$, weighted by the probabilities that there will be $0,1,2,(k-t)$ more units for sale. These equilibrium strategies have two other interesting properties. First, as Milgrom and Weber (1982) observe, the sequence of bids submitted by a given bidder is increasing when supply is certain. The intuition behind this pattern is that the ratio of remaining items to remaining bidders decreases as the auction proceeds from one stage to the next. As a result, this decrease in supply relative to demand induces buyers to bid more aggressively as the sequence unravels. However when supply is uncertain, equilibrium bids can be decreasing (or first decreasing and then increasing) for some sets of parameters $n, k, \delta$, and $F$. For very small values of $\delta$, bidders would perceive each stage $t$ as being likely to be the last one so that their bids would be very close to the single-unit RNNE bid for an auction with $n-t+1$ bidders. As this bid decreases with $t$, a small likelihood that the sequence will proceed to stage $t+1$ can, for given $n, k$ and $F$, offset the effect of a decrease in supply relative to demand (which induces a more aggressive bidding) and produce a lower equilibrium bid for stage $t+1$. Second, these equilibrium bids do not depend on past prices. This directly follows from the fact that buyers' resale values are identically and independently distributed. The following proposition states that equilibrium prices follow a martingale if supply is certain, that they are declining for any positive amount of supply uncertainty and that the decline is more severe as $\delta$ decreases.

Proposition 2: In sequential first-price auctions with private-independent values and unitdemands, if $\delta$ stands for the probability that one more auction will occur, then

1. the sequence of expected prices follows a martingale if $\delta=1$ [Milgrom and Weber, 1982]

$$
E\left\{b_{k-l}\left(X_{(k-l)}\right)\right\}=E\left\{b_{k-l-1}\left(X_{(k-l-1)}\right)\right\}
$$

2. the sequence of expected prices is declining for $\delta \in(0 ; 1)$ and the decline is more important as $\delta$ decreases, so that

$$
\begin{aligned}
& E\left\{b_{k-l}\left(X_{(k-l)}\right)\right\} \leq E\left\{b_{k-l-1}\left(X_{(k-l-1)}\right)\right\} \\
& \text { and } \\
& \frac{\Delta\left[E\left\{b_{k-l-1}\left(X_{k-l-1}\right)\right\}-E\left\{b_{k-l}\left(X_{k-l}\right)\right\}\right]}{\Delta \delta}<0
\end{aligned}
$$

Proof: See Appendix 2. 
Pezanis-Christou (1996) shows that similar predictions hold for the second-price auction mechanism and that both the first- and second-price formats generate the same expected revenues to the seller. It is worth noting that although the effect of such an uncertainty on the formation of bids is similar to the one of NDARA preferences, these two concepts remain fundamentally different. The latter expresses buyers' reluctance, for a given auction stage, to play a lottery which certainty equivalent can be obtained on payment of a risk premium while the former only characterizes a link between stages which is determined by bidders' common belief $\delta$ and $k$. To this extent, from an experimental standpoint, the presence of an uncertain supply may lead to a significant misbehavior if bidders do not correctly assess this common belief.

To test the predictions of these propositions, we assume values to be uniformly distributed on $[\underline{x} ; \bar{x}]$, so that by Proposition 1 the $k$-tuple of symmetric RNNE bidding strategies takes the following expression

$$
b_{k-l}(x)=\underline{x}+(x-\underline{x}) \cdot\left[\delta^{l} \cdot \frac{n-k}{n-(k-l)+1}+\sum_{i=0}^{l-1} \delta^{i}(1-\delta) \frac{n-k+l-i}{n-(k-l)+1}\right] \quad \text { for } l=1, \ldots, k-1 \text {, }
$$

and

$$
b_{k}(x)=\underline{x}+\left[\frac{n-k}{n-k+1}\right] \cdot(x-\underline{x}) \quad \text { for } l=0
$$

Since these equilibrium strategies are linear in $x$, we report in Figure 1 the RNNE bid-to-value ratios for each item assuming: $x \rightarrow U[0 ; 100], n=8, k=4$ and $\delta=0.6,0.8$ or 1.0. For these parameters, the following thirteen hypotheses about bidders' behavior and prices are derived from Propositions 1 and 2, and are tested in Section 3.

H1) Unit $t(t=1,2,3,4)$ is awarded to the bidder with the $t^{\text {th }}$ highest value,

$\mathrm{H} 2$ ) Bidders use monotone increasing bid functions in all treatments,

H3) Bids in stage $t$ are independent of the observed prices in stage $t-1$,

H4) Consecutive average bid-to-value ratios are increasing (except for the $1^{\text {st }}$ and $2^{\text {nd }}$ unit when $\delta=0.6$ ),

H5) Consecutive average bid-to-value ratios increase less as $\delta$ decreases,

H6) The average bid-to-value ratio of unit $t(t<4)$ increases as $\delta$ decreases, 
H7) The average bid-to-value ratios for the $4^{\text {th }}$ unit are stochastically equivalent across treatments,

H8) Average bid-to-value ratios are equal to the RNNE ones,

H9) Average prices are equal to the RNNE ones,

H10) The average price of unit $t(t<4)$ increases as $\delta$ decreases,

H11) The average prices of the $4^{\text {th }}$ unit are stochastically equivalent across treatments,

H12) The decrease of consecutive average prices decreases as $\delta$ increases,

H13) When supply is certain, average prices are trend-free.

Figure 1: Risk Neutral Nash Equilibrium (RNNE) Bid-to-Value Ratios

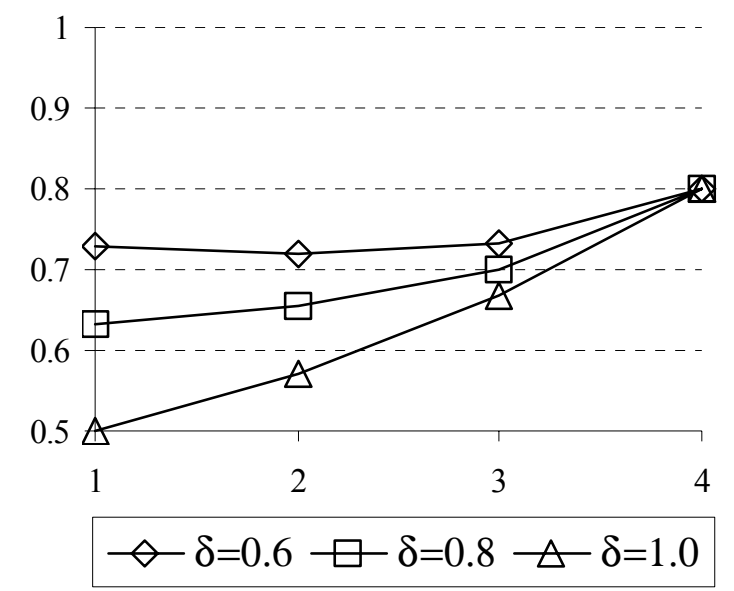

Theoretical Bid-to-Value Ratios

\begin{tabular}{ccccc} 
& & & & \\
\cline { 2 - 5 } & stage 1 & stage 2 & stage 3 & stage 4 \\
\hline$\delta=0.6$ & 0.728 & 0.720 & 0.733 & 0.800 \\
$\delta=0.8$ & 0.631 & 0.654 & 0.700 & 0.800 \\
$\delta=1.0$ & 0.500 & 0.571 & 0.667 & 0.800 \\
\hline
\end{tabular}

\section{Experimental Design}

The experiment was conducted in the Laboratory for Experimental Economics (LINEEX) at the University of Valencia. Subjects were recruited by public advertisement on campus and were mostly undergraduate students in economics. They were required to have never participated in other auction experiments and were allowed to participate in only one session. We considered three treatments, $\delta=0.6, \delta=0.8$ and $\delta=1.0$ and conducted three sessions per treatment. Henceforth, we will refer to these treatments as the $\delta 0.6, \delta 0.8$ and the $\delta 1.0$ treatments. At the outset of each session, subjects were given written instructions that were read aloud and were introduced to the computer software used for the experiment. ${ }^{2}$

\footnotetext{
${ }^{2}$ A translation of the instructions is reported in Appendix 2. The software was produced with the RatImage programming package (Abbink and Sadrieh, 1995).
} 
In each session, the pool of 16 subjects was divided into two independent groups (markets) of 8 subjects each. This way we were able to collect two independent sets of observations per session. Subjects stayed in the same market for the whole session and did not know who of the other subjects were in the same market as themselves. Each session consisted of 100 repetitions (rounds) of sequential first-price auctions and lasted for 2 to 3 hours. In each round, up to 4 identical units of a fictitious good were auctioned off one after the other. In each treatment, the first unit was always supplied, the second unit was supplied with probability $\delta$, the third unit with probability $\delta^{2}$, and the fourth unit with probability $\delta^{3}$. To determine whether an additional unit is sold in a given round (and to ensure that subjects understand the randomness and the independence of this event), a "Wheel of Fortune" was spun on the subjects' monitors. A unit was sold in approximately 10 seconds, and the average earning from participating in these experiments was $€ 8.45$ per hour. $^{3}$

Following the first-price auction rule, at each stage of a given round the item was awarded to the subject who submitted the highest bid at a price equal to his/her bid. If the highest bids were tied, a random procedure was used to determine the winner. Subjects who were already awarded a unit in a given stage were not allowed to participate in the remaining auction stages of that round. Hence whenever the last unit was put up for sale, there were only 5 bidders left in the auction.

At the outset of each round, each bidder received an integer private value which was drawn from a uniform distribution defined on [0;100]. Subjects knew their own value but not those of the others and they were informed that all values were drawn (with replacement) from the same distribution. It was explained that if they were awarded a unit, they would make a profit equal to the difference between their bid and the value they received in that round.

Subjects were required to bid in all stages and their bids were restricted to lie in the $[0 ; 100]$ interval so that bidding above one's private value was allowed. However, whenever they entered a bid above their value, a warning message popped up on the subject's terminal screen before they validated their bid, announcing a possible loss in case he/she was awarded the unit.

At any stage $t$ in a given round, subjects were informed about their value, the prices fetched so far, their cumulative profit (over the rounds played so far) and the updated probabilities that there will still be (4-t) more items for sale. At the end of each round, this

\footnotetext{
${ }^{3}$ At the time of the experiment, $1 €=1.06 \mathrm{US} \$$.
} 
information was appended to a "history window" that could be retrieved at any time during the experiment.

\section{Experimental Results}

Most of our conclusions refer to group average statistics (i.e., averages of individual averages) and are based on the outcomes of non-parametric tests for independent or related samples of independent observations (see Siegel and Castellan, 1988). The reported rejection probabilities assume samples of 6 independent observations and we reject the null hypotheses tested at a significance level of $\alpha=.05$. In the following sections, we start by checking the efficiency of allocations in the different treatments to give an overview of the outcomes, and we proceed with checking whether the data support the bid and price predictions of the Nash equilibrium.

\begin{tabular}{ccc}
\multicolumn{3}{c}{ Table 1: Average Efficiency } \\
(only & 4-stage sequences $)$ \\
\hline$\delta 0.6$ & $\delta 0.8$ & $\delta 1.0$ \\
$(127 \mathrm{obs})$ & $(318 \mathrm{obs})$ & $(600 \mathrm{obs})$ \\
\hline .997 & .992 & .989 \\
\hline \multicolumn{4}{c}{} \\
\multicolumn{3}{c}{ Cross-Treatment Comparisons } \\
\hline$\delta 0.6 \sim \delta 0.8$ & $\delta 0.8 \sim \delta 1.0$ & $\delta 0.6 \sim \delta 1.0$ \\
.065 & .240 & .002 \\
\hline Note: Mann-Whitney two-tailed test results; \\
significance levels in italics.
\end{tabular}

\subsection{Efficiency of allocations}

We measure the efficiency of allocations by the ratio of the sum of the values of the four winning bidders to the sum of the four highest values. A ratio smaller than one indicates that there still are some gains from trade to be exhausted or equivalently, that the allocations are inefficient. Table 1 reports the average efficiency statistics and the outcomes of MannWhitney tests that check for significant cross-treatment differences. These differences appear to be very small but they are significant when the $\delta 0.6$ treatment is compared to the $\delta 1.0$ treatment so that uncertainty improves, though slightly, the efficiency of allocations in fourstage sequences. The average efficiency levels for the $\delta 1.0$ treatment are also comparable to the $98 \%$ reported by Keser and Olson (1996) for a similar bidding environment. 


\section{Figure 2: Percentage of allocations of item $t$ to the buyer with}

the $1^{\text {st }}, 2^{\text {nd }}-, 3^{\text {rd }}$ - and $4^{\text {th }}$-highest values.

Treatment $\delta 0.6$

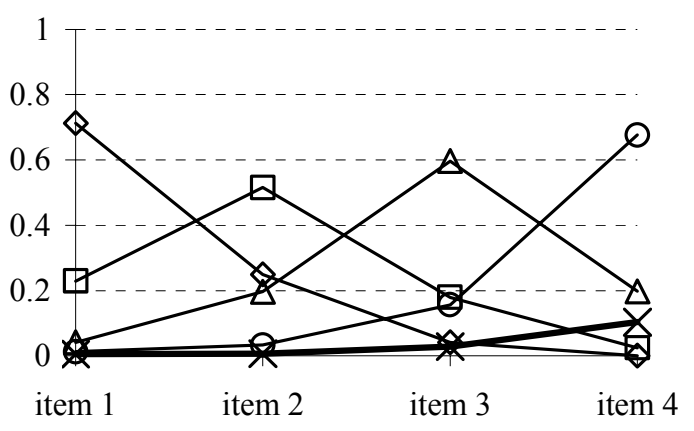

Treatment $\delta 1.0$

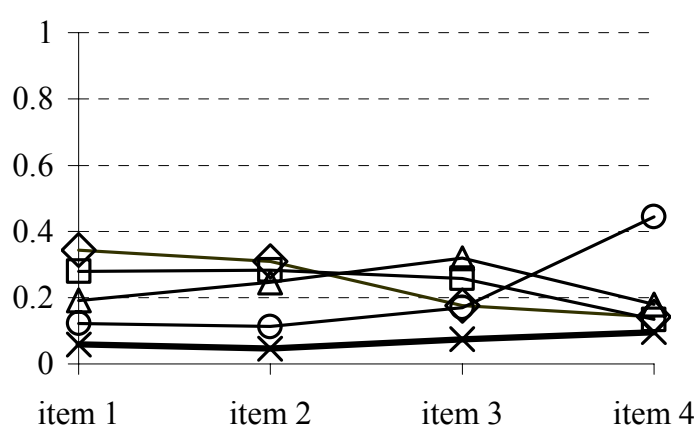

Treatment $\delta 0.8$

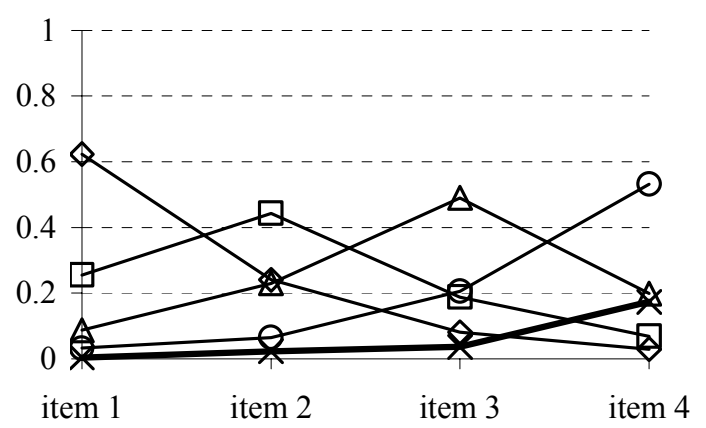

Figure 2 reports for each treatment the percentage of allocations of unit $t$ to the bidder with the highest value, the $2^{\text {nd }}$-highest, the $3^{\text {rd }}$-highest, the $4^{\text {th }}$-highest value and to a bidder with a value smaller than the $4^{\text {th }}$-highest one. Since in all treatments, the relative frequency of allocating unit $t$ to bidders with the $t^{\text {th }}$ highest values is far below the predicted $100 \%$, the data do not support H1. The plots further indicate that the likelihood for subjects with the $t^{\text {th }}$ highest value to be awarded the $t^{\text {th }}$ unit decreases as $\delta$ increases. When supply is certain, subjects with the highest value are equally likely to get the first or the second unit whereas subjects with the second highest value are equally likely to get any of the first three units sold. Furthermore, the likelihood that subjects with a value smaller than the $4^{\text {th }}$-highest are allocated one of the first three units is greater when $\delta=1$ than when $\delta<1$, which is in line with the finding that average efficiency decreases with $\delta$. This overview of allocations indicates that behavior changes whether supply is certain or not. While bidders with the $t^{\text {th }}$ highest value have the modal (relative) frequencies of allocations of units $t$ when supply is 
uncertain (as assumed in the equilibrium), they seem to "wait and see" the outcome of the first stage when supply is certain, thereby giving a chance to bidders with lower values to win in the early stages of a sequence.

\subsection{Bidding behavior}

\subsubsection{Monotone Increasing Strategies}

The lower efficiency of allocations when $\delta=1.0$ suggests that in this treatment bidders did not consistently use monotone increasing strategies, as is required by the RNNE prediction. To check this hypothesis (H2), we estimate piecewise-linear (spline) bid functions for each stage of each treatment (Greene, 2000), assuming four equal segments (i.e., one segment for values smaller then 25 , one for values between 25 and 50, one for values between 50 and 75 and one for values greater than 75). The plots of these bid functions are reported in Figure 3 and indicate that upon receiving a value greater than 50, subjects bid less aggressively (i.e., the slopes of the estimated bid functions are smaller) when supply is certain than when it is uncertain.

As the number of bid observations corresponding to values greater than 75 decreases as the auction proceeds, the estimation of the last segment for the last three stages does not characterize reliably an aggregate behavior. We therefore limit our discussion to the shape of the estimated bid functions for the first stage, in which all bidders of a given session participated.

The estimated bid functions for each group are reported in Appendix 3. The plots indicate that in three groups of the $\delta 1.0$ treatment, the last segments of these bid functions (for the first stage) have a negative slope whereas they are positive in all groups of the uncertainty treatments. The estimated negative slopes are equal to -.07 (Group 3) and -.03 (Group 4 and Group 6) and the regression outcomes (not reported here) indicate that the dummy estimates for these last segments are significant at $\alpha=.005$ in all treatments. When we estimate individual bid functions, $50 \%$ of subjects who participated in the $\delta 1.0$ treatment display a non-monotone behavior in the first stage whereas only $.4 \%$ and $15 \%$ of them did so in the $\delta 0.6$ and $\delta 0.8$ treatments. Such a behavior conflicts with the hypothesis of monotone increasing strategies and is more likely to be observed as the experiment proceeds since it is present in only two groups during the first 25 or 50 rounds but it is present in five groups when the estimation accounts for the last 50 rounds. 
The plots further suggest that in all stages of the certainty treatment, behavior is almost linear for values below or above 50 so that we proceed with testing all our bid predictions by looking at average bid-to-value ratios over the whole range of values as well as for values lower and greater than 50. Such a clustering of the data allows us to check the use of nonlinear strategies, and is consistent with subjects' written statements (collected at the end of the sessions) that they bid differently whether they received a "low" or a "high" value. Henceforth, we refer to a high (low) value bidder when a subject receives a value greater (smaller) than 50 in a given round.

Figure 3: Estimated Piecewise Linear (Spline) Bid Functions

Treatment $\delta 0.6$

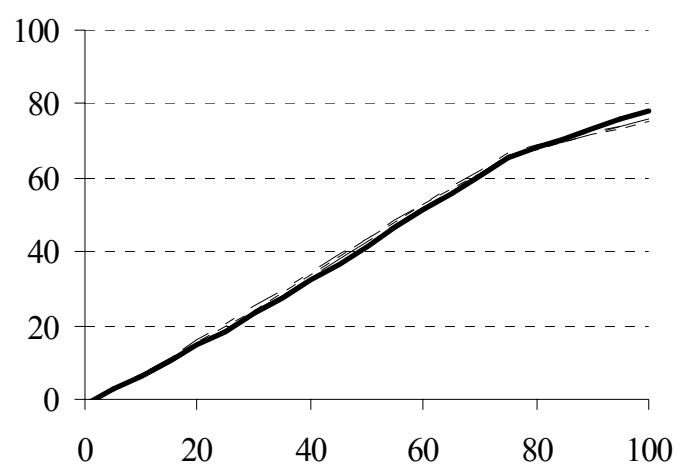

Treatment $\delta 1.0$

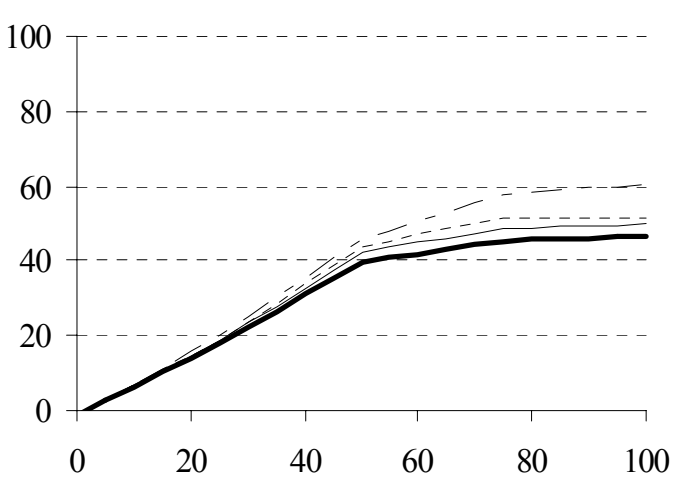

Treatment $\delta 0.8$

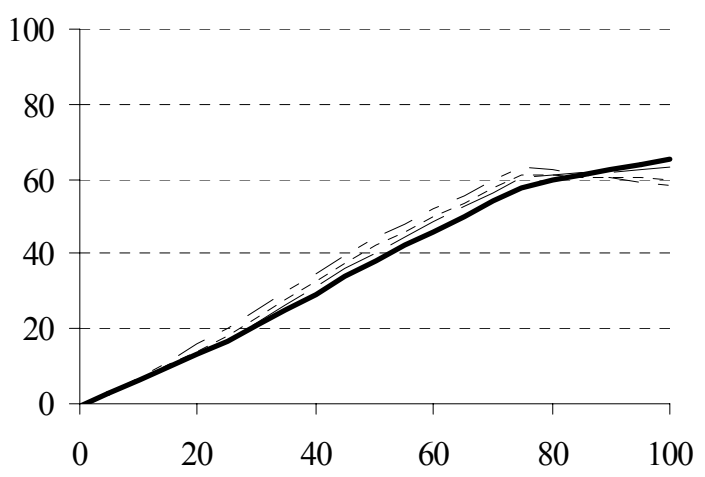

Table 2 reports the average differences between the bid-to-value ratios of low and high value bidders. These differences are usually significant and characterize a very different behavior whether supply is certain or not. When it is uncertain, subjects bid significantly more aggressively (i.e., their bid-to-value ratios are greater) upon receiving a high value than upon receiving a low value. This bid pattern is also more pronounced as supply is more uncertain. 
When it is certain, the opposite occurs: they bid less aggressively (for the first three units) when they receive a high value than when they receive a low value. To this extent, the presence of an uncertain supply would seem to discourage bidders from bidding actively when they receive a low value and to induce them to bid aggressively when they receive a high value. When supply is certain, the contrary would occur: the prospect that there are four units for sale seem to discourage high value bidders from bidding actively (especially in the first two rounds) and to trigger an aggressive bidding from low value bidders.

Table 2: Average Differences in Bid-to-Value Ratios of High and Low value bidders

\begin{tabular}{|c|c|c|c|c|c|c|c|c|c|c|c|}
\hline \multicolumn{4}{|c|}{ Treatment 80.6} & \multicolumn{4}{|c|}{ Treatment 80.8} & \multicolumn{4}{|c|}{ Treatment $\delta 1.0$} \\
\hline $1^{\text {st }}$ & $2^{\text {nd }}$ & $3^{\text {rd }}$ & $4^{\text {th }}$ & $1^{\mathrm{st}}$ & $2^{\text {nd }}$ & $3^{\text {rd }}$ & $4^{\text {th }}$ & $1^{\mathrm{st}}$ & $2^{\text {nd }}$ & $3^{\text {rd }}$ & $4^{\text {th }}$ \\
\hline .095 & .094 & .084 & .094 & .049 & .063 & .064 & .063 & -.098 & -.072 & -.038 & .017 \\
\hline .031 & .031 & .031 & .031 & .031 & .031 & .031 & .031 & .031 & .031 & .031 & .156 \\
\hline
\end{tabular}

\subsubsection{Independence of bids to past prices}

As bidders have independent private values and unit demands, their bids in stage $t+1$ should be independent of the prices observed in stage $t$. We test this hypothesis $(\mathrm{H} 3)$ by first computing for each bidder the Spearman rank correlation between the prices observed in stage $t$ and her/his bids in stage $t+1$. We then conduct a (two-tailed) Wilcoxon Signed Ranks test on the average correlation coefficients of a group to check if they are significantly different from 0 or not. The test outcomes are reported in Table 3 and indicate that the average correlation coefficients are significantly different from 0 (positive) only in the $\delta 1.0$ treatment. When a distinction is made between high and low value bidders, the outcomes further reveal that the information on past prices is relevant only to high value subjects and when $\delta=0.8$ or 1.0 so that in these treatments, high value bidders would "anchor" their bids for stage $t+1$ to the prices observed in stage $t$. 
Table 3: Average Correlation Coefficients Between Bids and Past Prices

\begin{tabular}{|c|c|c|c|c|c|c|c|c|c|}
\hline & \multicolumn{3}{|c|}{ Treatment $\delta 0.6$} & \multicolumn{3}{|c|}{ Treatment $\delta 0.8$} & \multicolumn{3}{|c|}{ Treatment $\delta 1.0$} \\
\hline & Cor $_{1}$ & $\mathrm{Cor}_{2}$ & $\mathrm{Cor}_{3}$ & Cor $_{1}$ & $\mathrm{Cor}_{2}$ & $\mathrm{Cor}_{3}$ & $\mathrm{Cor}_{1}$ & $\mathrm{Cor}_{2}$ & $\mathrm{Cor}_{3}$ \\
\hline All & .139 & .216 & .186 & .135 & .239 & .331 & .140 & . 215 & .288 \\
\hline $\mathrm{H}$ & .261 & .392 & .410 & .312 & .459. & .599 & .343 & .514 & .461. \\
\hline $\mathrm{L}$ & -.064 & -.079 & -.060 & -.015 & .023 & .094 & .019. & .029 & . 107 \\
\hline All & .917 & .116 & .463 & .116 & .173 & .463 & .028 & .028 & .028 \\
\hline $\mathrm{H}$ & .600 & .249 & .345 & .028 & .028 & .028 & .028 & .028 & .028 \\
\hline $\mathrm{L}$ & .345 & .345 & .028 & .600 & .345 & .600 & .463 & .463 & .753 \\
\hline
\end{tabular}

\subsubsection{Increasing Consecutive Bid-to-Value Ratios}

The predicted changes in consecutive bid-to-value ratios reflect how the competitive pressure evolves throughout the sequence of a given treatment. Table 4 reports the expected and observed (average) bid-to-value ratios as well as the outcomes of a Wilcoxon Rank Sum test for within-treatment comparisons. The null hypothesis of equal consecutive bid-to-value ratios is rejected in all stages of the $\delta 0.8$ and the $\delta 1.0$ treatments in favor of the alternative that they increase from one stage to another. As this is observed for both low and high value bidders, the prediction of increasing consecutive bid-to-value ratios is supported by the data when $\delta=.8$ and 1.0. For the $\delta 0.6$ treatment, the increments of average bid-to-value ratios from the first to the second stage are increasing (significantly) whereas they should be decreasing, and they are stochastically equivalent for the last two stages whereas they should be increasing. As this pattern holds for both low and high value bidders, the observed behavior would thus not fully support the RNNE predictions for this treatment. However, the declining proportion of subjects who increase their three consecutive average bid-to-value ratios as $\delta$ decreases (i.e., $79 \%, 52 \%$ and $21 \%$ for $\delta=1.0,0.8$ and 0.6 , respectively) suggest that this hypothesis (H4) still holds qualitatively as supply is more uncertain.

Table 5 reports the outcomes of cross-treatment comparisons. The hypothesis tested in the upper panel is that the change in average bid-to-value ratios from one stage to another increases less as $\delta$ decreases (H5). Those tested in the lower panel are that the average bid-tovalue ratio in stage $t<4$ increases as $\delta$ decreases (H6) and that average bid-to value ratios for the last stage $t=4$ are equal across treatments (H7). The test results support H6 and H7 since they reject the null of equal average ratios for the first three stages and they do not reject it for the last stage. However, the data do not support H5 when the $\delta 0.8$ and $\delta 1.0$ treatments are 
compared. Also, the behavior of low value bidders does not support H5 and H6 and the one of high value bidders does not support $\mathrm{H} 7$ when the $\delta 0.8$ and $\delta 1.0$ treatments are compared. We provide an intuition for such inconsistencies with the RNNE predictions in the next section.

Table 4: Average Bid-to-Value Ratios and Within-Treatment Comparisons

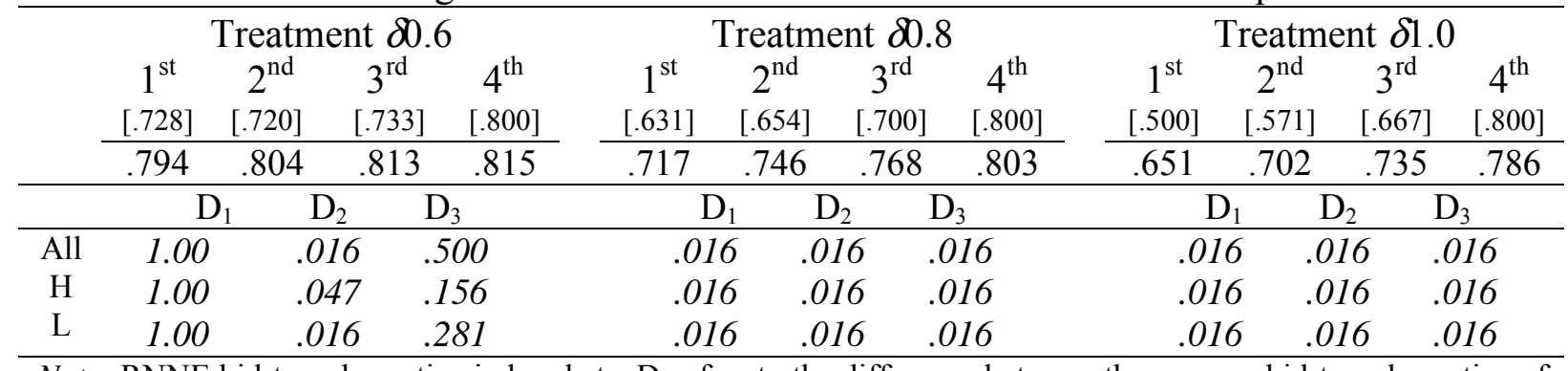

Note: RNNE bid-to-value ratios in brackets; $\mathrm{D}_{\mathrm{t}}$ refers to the difference between the average bid-to-value ratios of stage $t$ and those of stage $t+1$. Wilcoxon Signed Ranks one-tailed test results; significance levels in italics; All: All bidders; H: High-value bidders; L: Low-value bidders.

Table 5: Cross-Treatment Comparisons of Differences

\begin{tabular}{lcccc}
\hline & & $\mathrm{D}_{1}$ & $\mathrm{D}_{2}$ & $\mathrm{D}_{3}$ \\
\hline$\delta 0.6 \sim \delta 0.8$ & All & .001 & .021 & .021 \\
& $\mathrm{H}$ & .002 & .002 & .033 \\
& $\mathrm{~L}$ & .090 & .066 & .033 \\
\hline$\delta 0.8 \sim \delta 1.0$ & All & .008 & .047 & .090 \\
& $\mathrm{H}$ & .066 & .047 & .001 \\
& $\mathrm{~L}$ & .409 & .954 & .531 \\
\hline
\end{tabular}

Cross-Treatment Comparisons of Average Bid-to-Value Ratios

\begin{tabular}{lccccc}
\hline & & $1^{\text {st }}$ & $2^{\text {nd }}$ & $3^{\text {rd }}$ & $4^{\text {th }}$ \\
\hline$\delta 0.6 \sim \delta 0.8$ & All & .002 & .004 & .047 & $.394^{\ddagger}$ \\
& $\mathrm{H}$ & .001 & .001 & .021 & $.132^{\ddagger}$ \\
& $\mathrm{L}$ & .021 & .047 & .047 & $.818^{\ddagger}$ \\
\hline$\delta 0.8 \sim \delta 1.0$ & All & .004 & .033 & .033 & $.310^{\ddagger}$ \\
& $\mathrm{H}$ & .001 & .001 & .001 & $.015^{\ddagger}$ \\
& $\mathrm{L}$ & .650 & .803 & .706 & $.699^{\ddagger}$ \\
\hline Note: $\quad$ Mann-Whitney & one-tailed & test & results; & $\vdots$ & two-tailed \\
& &
\end{tabular}
significance levels in italics; $D_{t}$ refers to the difference between the average bid-to-value ratios of stage $t$ and those of stage $t+1$. All: All bidders; H: High-value bidders; L: Low-value bidders.

\subsubsection{Risk Neutral Nash Equilibrium Bidding}

Table 6 reports statistics on average deviations from the RNNE bid-to-value ratios. The test outcomes indicate that in all treatments, we reject the null of RNNE bid-to-value ratios (H8) for the first three stages in favor of a significant overbidding, but not for the fourth stage. We also checked for "learning trends" and found no significant convergence of behavior to the 
RNNE predictions as the experiment proceeds, so that these bid patterns appear to be persistent over time. ${ }^{4}$

Table 6: Average Deviations from RNNE Bid-To-Value Ratios

\begin{tabular}{|c|c|c|c|c|c|c|c|c|c|c|c|c|}
\hline & \multicolumn{4}{|c|}{ Treatment 80.6} & \multicolumn{4}{|c|}{ Treatment 80.8} & \multicolumn{4}{|c|}{ Treatment $\delta 1.0$} \\
\hline & $1^{\text {st }}$ & $2^{\text {nd }}$ & $3^{\mathrm{rd}}$ & $4^{\text {th }}$ & $1^{\mathrm{st}}$ & $2^{\text {nd }}$ & $3^{\mathrm{rd}}$ & $4^{\text {th }}$ & $1^{\mathrm{st}}$ & $2^{\text {nd }}$ & $3^{\text {rd }}$ & $4^{\text {th }}$ \\
\hline & .066 & .084 & .080 & .015 & .086 & .092 & .068 & .003 & .151 & .130 & .069 & -.014 \\
\hline All & .031 & .031 & .031 & .313 & .031 & .031 & .031 & .688 & .031 & .031 & .031 & .063 \\
\hline $\mathrm{H}$ & .031 & .031 & .031 & .031 & .031 & .031 & .031 & .031 & .031 & .031 & .031 & 1.00 \\
\hline $\mathrm{L}$ & .156 & .031 & .031 & .313 & .063 & .031 & .031 & .438 & .031 & .031 & .031 & .063 \\
\hline
\end{tabular}

According to previous studies of bidding behavior in single-unit first-price auctions with private-independent values (Cox, Roberson and Smith, 1982, and Cox, Smith and Walker, 1988), our data would suggest that bidders behave as if they were risk averse for the first three units and as if they were risk neutral for the fourth unit. However, McAfee and Vincent (1993) show that for such sequential auctions, increasing symmetric Nash equilibrium strategies do not exist if buyers display constant relative risk averse (DARA) preferences and that allocations are not necessarily efficient. As this non-existence of increasing equilibrium strategies holds for $\delta \leq 1$, the presence of an overbidding and the use of monotone increasing strategies for the first stage of the uncertainty treatments do not support the hypothesis of constant relative risk aversion. If subjects were assumed to have NDARA preferences, then they should display monotone increasing strategies when $\delta=1$ and their final bids should be greater than risk neutral ones. As the observed behavior does not support the latter two predictions, it appears that neither the DARA nor the NDARA hypothesis can consistently explain the observed behavior.

In what follows, we provide a rational for the bid patterns observed in the uncertainty treatments by casting the behavioral hypothesis that bidders formulate a belief $\delta^{*}$ about the true probability $\delta$. We assume in particular that before the first stage takes place, bidders formulate a pessimistic belief $\delta_{1}^{*}<\delta$ about the probability of occurrence of a second stage, and that a losing bid in stage $t$ reinforces this pessimistic belief $\delta_{1}^{*}$ for stage $t+1$, so that

\footnotetext{
${ }^{4}$ We checked for convergence by testing whether the average absolute difference between observed and RNNE bid-to value ratios was decreasing or not over time with Spearman correlation tests. We also checked if the average absolute deviation from RNNE was greater in the 25 first rounds than in the 25 last rounds and found no significant pattern.
} 
$\delta_{t+1}^{*} \leq \delta_{t}^{*}<\delta$ for $t=1,2$. Since there is no more uncertainty about future supplies once the fourth stage is reached, this hypothesis would not explain overbidding in the last stage of a sequence. To this extent, the non-rejection of the RNNE prediction for the last stage of these treatments would support this behavioral hypothesis.

Table 7 reports for each of the first three stages of the uncertainty treatments, the highest estimate of $\delta_{i}^{*}$ such that deviations from the corresponding RNNE bid-to-value ratios would not be significant. The figures suggest that in both of these treatments, subjects' bid as if $\delta_{1}^{*}<\delta$ and as if these beliefs worsen as the sequence unravels. Notice that with such beliefs for the 80.6 treatment, consecutive equilibrium bids would also be increasing for the first three stages, which is line with the test outcomes reported in Table $4 .^{5}$

Table 7: Estimated Beliefs $\delta_{i}^{*}$ when $\delta=0.6$ and $\delta=0.8$

\begin{tabular}{|c|c|c|c|c|c|c|}
\hline \multirow{3}{*}{$\delta_{i}^{*}$} & \multicolumn{3}{|c|}{ Treatment $\delta 0.6$} & \multicolumn{3}{|c|}{ Treatment $\delta 0.8$} \\
\hline & $1^{\text {st }}$ & $2^{\text {nd }}$ & $3^{\text {rd }}$ & $1^{\text {st }}$ & $2^{\text {nd }}$ & $3^{\text {rd }}$ \\
\hline & $\begin{array}{c}0.45 \\
{[.782]}\end{array}$ & $\begin{array}{c}0.3 \\
{[.801]}\end{array}$ & $\begin{array}{c}0.15 \\
{[.808]}\end{array}$ & $\begin{array}{c}0.65 \\
{[.707]}\end{array}$ & $\begin{array}{c}0.60 \\
{[.720]}\end{array}$ & $\begin{array}{c}0.55 \\
{[.742]}\end{array}$ \\
\hline & .011 & .002 & .005 & .011 & .026 & .027 \\
\hline & .156 & .563 & .438 & .689 & .219 & .219 \\
\hline $\begin{array}{l}\text { Note: Av } \\
\text { from RN } \\
\text { Sioned R }\end{array}$ & $\begin{array}{l}\text { JE bid } \\
\text { value }\end{array}$ & lue ra & $\begin{array}{l}\text { sssumi } \\
\delta_{i}^{*} ; \mathrm{s}\end{array}$ & $\mathrm{n}$ brac & Avera & viation \\
\hline
\end{tabular}

When we check the bidding behavior of low and high value bidders, the figures in Table 6 show a significant overbidding for the latter in all stages and no overbidding for low value bidders in the first and fourth stages. In terms of our misperception hypothesis, high value bidders would be more likely to formulate pessimistic beliefs about the available supply as the auction proceeds than low value bidders. Also, as the differences between the consecutive bid increments of high and low value bidders are not significant from one stage to another (cf. Table A in Appendix 4), losing an auction-stage would equally affect their behavior. To this extent, the overbidding by high value bidders in the last stage of the uncertainty treatments

\footnotetext{
${ }^{5}$ For this treatment, an estimate of $\delta_{3}^{*}=0.2$ would yield an equilibrium bid-to-value ratio of 0.8 for the third stage; the same as the one expected for the fourth stage. Therefore, the previous finding that average bid-to value ratios for the last two stages were stochastically equivalent (cf. Table 4) would be supported by this hypothesis. However, with such an estimate, average deviations from the corresponding RNNE bid-to-value ratios would not be significant only at $\alpha=.10$, so that we opted the more conservative estimate of $\delta_{3}^{*}=0.15$.
} 
could be seen as the result of the negative feedback from losing the three previous stages while having a value greater than 50 .

In the supply certainty treatment, subjects' bidding departs from the RNNE predictions in the first three stages of a sequence but we cannot reject this prediction in the last stage for both types of bidders. Since in this treatment, competition increases as the sequence of auctions proceeds, the larger consecutive bid increments by high value bidders suggest that those bidders who did not bid aggressively in the early stages can be expected to increase their consecutive bids more than those who started off by bidding aggressively (cf. Table A in Appendix 4). Also, the previous findings that $i$ ) bidders tend to use non-monotone increasing strategies for the first stage, $i i)$ they increase their bids with past prices when they receive high values and iii) we cannot reject the RNNE prediction for high value bidders in the first stage, suggest that upon receiving a high value in this treatment, subjects "wait-and-see", i.e., they start by not bidding aggressively (i.e., submitting RNNE bids) and by bidding more aggressively as the auction proceeds. The aggressive bidding of subjects who receive low values would then be motivated by the prospect of making a profit if those subjects who receive a high value bid too low on these first units. Such an ex-post asymmetric behavior, which is not supported by the symmetric predictions of the model, would also explain the lower percentages of allocations of the first three items in this treatment (cf. Figure 2).

\subsection{Price behavior}

\subsubsection{Average Prices and Cross-Treatment Comparisons}

A foreseeable consequence of overbidding in first-price auctions is that the observed prices should exceed those expected in the RNNE. We report in Table 8 the "expected" and the observed average price statistics. ${ }^{6}$ A series of one-tailed Wilcoxon Signed Ranks test (not reported here) indicate that we reject the null hypothesis (H9) of equality in favor of the alternative that average prices are greater than expected in all stages of all treatments (in all cases, $p=.016$ ). Such a rejection for the last stage therefore suggests that only winning bids were significantly greater than those expected in the RNNE.

We check whether the average price in stage $t<4$ increases with supply uncertainty (H10) and whether it is equal across treatments for the last stage (H11) with one-tailed MannWhitney tests. The test outcomes are reported in the lower panel of Table 9. As the null

\footnotetext{
${ }^{6}$ The "expected" price statistics are the ones that would be observed if all bidders submitted RNNE bids.
} 
hypothesis of equality is rejected for all $t<4$ but not when $t=4$, the data supports both predictions. $^{7}$

Table 8: Average Prices and Within-Treatment Comparisons

\begin{tabular}{ccccccccccccccc}
\hline \multicolumn{3}{c}{ Treatment $\delta 0.6$} & \multicolumn{4}{c}{ Treatment $\delta 0.8$} & \multicolumn{4}{c}{ Treatment $\delta 1.0$} \\
$1^{\text {st }}$ & $2^{\text {nd }}$ & $3^{\text {rd }}$ & $4^{\text {th }}$ & & $1^{\text {st }}$ & $2^{\text {nd }}$ & $3^{\text {rd }}$ & $4^{\text {th }}$ & & $1^{\text {st }}$ & $2^{\text {nd }}$ & $3^{\text {rd }}$ & $4^{\text {th }}$ \\
{$[64.8]$} & {$[56.2]$} & {$[49.6]$} & {$[45.9]$} & & {$[56.1]$} & {$[51.1]$} & {$[46.8]$} & {$[45.3]$} & & {$[44.7]$} & {$[44.6]$} & {$[44.7]$} & {$[44.9]$} \\
\hline 75.5 & 67.8 & 60.7 & 52.5 & & 66.8 & 61.0 & 55.1 & 49.6 & & 51.7 & 51.0 & 50.2 & 49.5 \\
\hline $\mathrm{D}_{1}(\mathrm{p})$ & $\mathrm{D}_{2}(\mathrm{p})$ & $\mathrm{D}_{3}(\mathrm{p})$ & & $\mathrm{D}_{1}(\mathrm{p})$ & $\mathrm{D}_{2}(\mathrm{p})$ & $\mathrm{D}_{3}(\mathrm{p})$ & & $\mathrm{D}_{1}(\mathrm{p})$ & $\mathrm{D}_{2}(\mathrm{p})$ & $\mathrm{D}_{3}(\mathrm{p})$ \\
.016 & .016 & .016 & & .016 & .016 & .016 & & $.219^{*}$ & $.219^{\sharp}$ & $.844^{\sharp}$ \\
\hline
\end{tabular}

Note: RNNE price predictions in brackets; $\mathrm{D}_{\mathrm{t}}(\mathrm{p})$ refers to the difference between the average prices of stage $t$ and those of stage $t+1$; Wilcoxon Signed Ranks one-tailed test results; ${ }^{\sharp}$ : two-tailed test results.

Table 9: Cross-Treatment Comparisons of Differences

\begin{tabular}{lccc}
\hline & $\mathrm{D}_{1}(\mathrm{p})$ & $\mathrm{D}_{2}(\mathrm{p})$ & $\mathrm{D}_{3}(\mathrm{p})$ \\
\hline$\delta 0.6 \sim \delta 0.8$ & .033 & .008 & .001 \\
$\delta 0.8 \sim \delta 1.0$ & .001 & .001 & .001 \\
\hline
\end{tabular}

\begin{tabular}{ccccc}
\multicolumn{5}{c}{ Cross-Treatment Comparisons of Averages Prices } \\
\hline & $1^{\text {st }}$ & $2^{\text {nd }}$ & $3^{\text {rd }}$ & $4^{\text {th }}$ \\
\hline$\delta 0.6 \sim \delta 0.8$ & .001 & .001 & .001 & $.180^{\ddagger}$ \\
$\delta 0.8 \sim \delta 1.0$ & .001 & .001 & .001 & $.699^{\ddagger}$ \\
\hline
\end{tabular}

Note: Mann-Whitney one-tailed test results; : two-tailed test results; significance levels in italics; $\mathrm{D}_{\mathrm{t}}(\mathrm{p})$ refers to the difference between the average prices of stage $t$ and those of stage $t+1$.

\subsubsection{Price Trends}

According to Proposition 2, average prices should decline when supply is uncertain and they should be constant when supply is certain. We test these predictions by means of a series of Wilcoxon Rank Sum tests on the average price samples of each treatment and by means of a series of Mann-Whitney tests that check that the average difference of consecutive average prices decreases with $\delta(\mathrm{H} 12)$. The test outcomes are reported in Tables 8 and in the upper panel of Table 9, respectively. Both tests reject the null hypotheses of equality in favor of the alternative that average prices decline when supply is uncertain and the statistics of Table 8 indicate that we cannot reject the trend-free prediction (H13) of Milgrom and Weber (1982) when supply is certain.

This trend-free result contrasts with the declining price pattern reported by Keser and Olson (1996) for a similar bidding environment (i.e., $n=8, k=4$ and $\mathrm{U}[0 ; 1000]$ ) but in

\footnotetext{
${ }^{7}$ We also conducted a Kruskal-Wallis test that does not reject (at $\alpha=.10$, two-tailed) the null hypothesis of equal average price distributions across the four stages of this treatment.
} 
which subjects played for only 20 rounds. Given that the multi-period nature of these markets makes bidding a rather complicated task for subjects, a possible reason for not observing trend-free prices in Keser and Olson (1996) could be the subjects' lack of bidding experience. When we conduct our analysis of price behavior for the first 20 rounds of the $\delta 1.0$ treatment, we also find a significant decline in average prices, so that subjects' experience in these previous experiments may indeed have been too limited for the Law-of-One-Price to be verified.

\section{Concluding remarks}

In this paper we analyze the effects of an uncertain supply on the formation of bids and prices in sequential first-price auctions with private-independent values and unit demands. We determine the symmetric risk neutral equilibrium bidding strategies for such an environment and test our predictions with experimental data. Despite a significant overbidding and the systematic violation of the quantitative predictions for the first three stages of a sequence, we find that most risk neutral Nash equilibrium predictions are qualitatively supported by the data. For the last stage of a sequence, the observed bidding behavior supports the quantitative predictions of this model, whether supply is certain or not.

Although bidders are ex-ante symmetric in their preferences (i.e., their values are drawn with replacement from the same distribution), their behavior changes considerably whether supply is certain or not and whether they receive a high or low value. When supply is uncertain, subjects' behavior supports well the risk neutral Nash equilibrium predictions if we cast the behavioral hypothesis that they formulate pessimistic beliefs about the occurrence of future stages and that these beliefs worsen as the sequence proceeds. When supply is certain, $50 \%$ of subjects display a non-monotone behavior for the first stage of a sequence that consists in not bidding aggressively upon receiving a high value and in bidding aggressively upon receiving a low value. Such a change in behavior across treatments cannot be captured by the usual risk aversion hypothesis and suggests that the apparently innocuous feature of supply uncertainty can have a significant impact on bidders' behavior. Also, the fact that prices are trend-free when supply is certain shows that the "Law-of-One-Price" may well obtain even if bidders adopt an asymmetric behavior once they receive their respective values.

Clearly many other features of real-world auctions still need to be taken into account to fully assess the effects of an uncertain supply on bids and prices in sequential auctions; these include bidders' multi-unit demands and the presence of affiliated values and/or asymmetric 
preferences. However, we believe that the model we study captures well the strategic implications of an uncertain supply on the formation of bids and prices, and that its laboratory testing provides some first insights into buyers' behavior in such markets.

\section{References}

Abbink K. and A. Sadrieh, 1995, "Ratimage, Research Assistance Toolbox for ComputerAided Human Behavior Experiments”, Discussion paper B-325, University of Bonn.

Ashenfelter O.C., 1989, "How auctions work for wine and art", Journal of Economic Perspectives, 3, 23-36.

Ashenfelter O.C. and D. Genesove, 1990, "Testing for price anomalies in real-estate auctions", American Economic Review, Papers and Proceedings, 82(2), 501-505.

Beggs A. and K. Graddy, 1998, "Declining values and the afternoon effect: evidence from the art auctions", RAND Journal of Economics, 28(3), 544-565.

Bernhardt D. and D. Scoones, 1994, "A note on sequential auctions", American Economic Review, 84, 653-657.

Black J. and D. De Meza, 1992, "Systematic price differences between successive auctions are no anomaly", Journal of Economics and Management Strategy, 1, 607-628.

Burguet R. and J. Sákovicz, 1997, "Sequential auctions with supply or demand uncertainty", Spanish Review of Economics, 14(1), 23-40.

Burns P., 1985, "Experience and decision-making: A comparison of students and businessmen in a simulated progressive auction," Research in Experimental Economics III, 139-157.

Cassady R. Jr., 1967, Auctions and Auctioneering (University of California Press, Berkeley).

Chen K.-Y. and C.R. Plott, 1998, "Nonlinear Behavior at Sealed Bid First Price Auctions," Games and Economic Behavior, 25,34-78.

Cox J.C., B. Roberson and V.L. Smith, 1982, "Theory and behavior of single object auctions", in V.L. Smith (ed.), Research in Experimental Economics, vol. 2, Greenwich, CT: JAI Press, pp 1-43.

Cox J.C., Smith V.L. and Walker J.M., 1988, "Theory and individual behavior of first-price auctions," Journal of Risk and Uncertainty, 1, 61-99.

Engelbrecht-Wiggans R., 1994, "Sequential auctions of stochastically equivalent objects", Economics Letters, 44, 87-90. 
Frahm D.G. and L.F. Schrader, 1970, "An experimental comparison of pricing in two auction systems", American Journal of Agricultural Economics, 52, 528-534.

Gale I.L. and D.B. Hausch, 1994, "Bottom-fishing and declining prices in sequential auctions", Games and Economic Behavior, 7, 318-331.

Gandal N., 1997, "Sequential auctions of interdependent objects: Israeli cable television licenses", Journal of Industrial Economics, XLV(3),227-243.

Ginsburgh V., 1998, "Absentee bidders and the declining price anomaly in wine auctions", Journal of Political Economy, 106(6), 1302-1319.

Greene W., 2000, Econometric Analysis, Prentice Hall.

Hausch D.B., 1986, "Multi-Object Auctions: Sequential vs. Simultaneous Sales", Management Science, 32, 1599-1610.

Hausch D.B., 1988, “A Model of Sequential Auctions”, Economics Letters, 26(3), 227-233.

Jeitschko T.D., 1999, "Equilibrium Price Paths in Sequential Auctions with Stochastic Supply”, Economics Letters, 64, 67-72.

Kagel J.H. (1995), "Auctions: A Survey of Experimental Research" in Handbook of Experimental Economics, Kagel J.H. and Roth A.E. (eds), Princeton University Press

Kagel J.H., R.M. Harstad and D. Levin (1987), "Information Impact and Allocation Rules in Auctions with Affiliated Private Values: A Laboratory Study", Econometrica, 55(6), 12751304.

Katok E. and Kwasnica A.M. (2002), “Time is Money: The effect of clock speed on seller's revenue in Dutch auctions", mimeo, Penn State University.

Katzman, B.E. (1999), “A Two Stage Sequential Auction with Multi-unit Demands”, Journal of Economic Theory, 86(1), 77-99.

Keser C. and M. Olson, 1996, "Experimental examination of the declining price anomaly", in Ginsburgh, V. and P.M. Menger (eds.), Economics of the Arts: Selected Essays (North Holland).

Laffont J.-J., P. Loisel and J. Robert, 1998, "Intra-day dynamics in sequential auctions: theory and estimation", mimeo, Université de Toulouse, IDEI.

Laffont J.-J., P. Ossard and Q. Vuong, 1995, "Econometrics of First-Price Auctions", Econometrica, 63(4), 953-980.

Laffont J.-J. and J. Tirole, 1993, A theory of procurement and regulation (MIT Press).

McAfee R.P. and D. Vincent, 1993, “The declining price anomaly", Journal of Economic Theory, 60, 191-212. 
Milgrom P.R. and R.J. Weber, 1982, "A theory of auctions and competitive bidding: Part 2", mimeo, Northwestern University. Published in "The Economic Theory of Auctions", P. Klemperer (Ed.), Edward Elgar Publishing, 2000.

Pezanis-Christou P., 1996, "Sequential Auctions with Supply Uncertainty", School of Economics Discussion Paper \#96/15, University of New South Wales.

Pitchik C. and A. Schotter, 1988, "Perfect Equilibria and Budget Constraints in Sequential Auctions: An Experimental Study", RAND Journal of Economics, 19(3), 363-388.

Siegel S. and N.J. Castellan, 1988, "Nonparametric statistics for the behavioral sciences", McGraw Hill.

Vickrey W., 1961, "Counter-speculation, auctions, and competitive sealed tenders", Journal of Finance, 16, 8-37.

von der Fehr, N.-H. M., 1994, "Predatory bidding in sequential auctions", Oxford Economic Papers, 46, 345-356. 


\section{Appendix 1: Proof of Propositions 1 \& 2}

The proofs closely follow those of Milgrom and Weber (1982) and McAfee and Vincent (1993).

\section{Proof of Proposition 1:}

The proof casts the following Lemma, proved in Laffont and Tirole (1993, p.121).

Lemma A: Consider a twice continuously differentiable function $\Pi(r, x, b(r)) \rightarrow \mathrm{R}$ where $b($.$) is a continuous monotonic function of r$. If $\left.\partial_{r} \Pi(r, x, b(r))\right|_{r=x}=0$ then sufficient conditions are also satisfied: $r=x$ represent a global optimum for $\Pi(., .,$.$) .$

To determine the symmetric equilibrium bidding strategies, it is convenient to consider the standpoint of a given buyer whose value is $x$ and who defines $Y_{1}>Y_{2}>$.. $>Y_{n-1}$ as the order statistics of the $(n-1)$ other values. As all values are independently and identically drawn from a well-defined distribution $F($.$) defined on \mathrm{R}_{+}$, the distribution of $Y_{l}$ given the realization of $Y_{l-1}=y_{l-1}$ and its density are defined as

$$
F_{Y_{l}}\left(\zeta \mid y_{l-1}\right)=\left[\frac{F(\zeta)}{F\left(y_{l-1}\right)}\right]^{n-l} \text { and } f_{Y_{l}}\left(\zeta \mid y_{l-1}\right)=\frac{(n-l) F(\zeta)^{n-l-1} f(\zeta)}{F\left(y_{l-1}\right)^{n-l}}
$$

with $F_{Y_{t}}\left(. \mid y_{1}, y_{2}, \ldots, y_{t-1}\right)=F_{Y_{t}}\left(. \mid y_{t-1}\right)$. The symmetric equilibrium bidding strategy at period $t$ given the observed realizations of $Y_{1}, Y_{2}, \ldots, Y_{t-1}$ is denoted by $b_{t}\left(., y_{1}, \ldots, y_{t-1}\right)$ and the expression $\left.\partial_{r} \Pi(r, x, b(r))\right|_{r=x}$ stands for the first derivative of $\Pi(r, x, b(r))$ with respect to $r$.

The proof proceeds in two steps. It is first shown that if buyers use increasing bidding strategies then, in any given stage $t$ a bidder can do no better then to bid $b$ a function of $\min \left\{x, y_{t-1}\right\}$. This is done recursively by starting from the last auction stage and by using a subgame perfection argument. At each stage $t$, a bidder will estimate his eventual gain or loss from deviating from the symmetric equilibrium strategy given that all other bidders adopt the equilibrium strategy and that he will bid at equilibrium in all subsequent stages. The equilibrium bidding strategies are then determined in a second step.

If the $k^{\text {th }}$ auction stage takes place, a bidder's expected profit from deviating in the $k^{\text {th }}$ stage by bidding as if he has a value $r_{k} \neq x$ given that he inferred from the previous winning bids the $(k-1)$ highest values, takes the following expressions. 


$$
\Pi_{k}\left(r_{k}, x, b\left(r_{k}\right)\right)= \begin{cases}\int_{0}^{r_{k}}\left[x-b_{k}\left(r_{k}, y_{1}, . ., y_{k-1}\right)\right] f_{Y_{k}}\left(\alpha \mid y_{k-1}\right) d \alpha & \\ =\left[x-b_{k}\left(r_{k}, y_{1}, . ., y_{k-1}\right)\right]\left[\frac{F\left(r_{k}\right)}{F\left(y_{k-1}\right)}\right]^{n-k}, & \text { if } r_{k} \leq y_{k-1} \\ {\left[x-b_{k}\left(r_{k}, y_{1}, . ., y_{k-1}\right)\right],} & \text { if } r_{k}>y_{k-1}\end{cases}
$$

The first order condition requires that $\left.\partial_{r_{k}} \Pi_{k}\left(r_{k}, x, b\left(r_{k}\right)\right)\right|_{r_{k}=x}=0$. From Lemma A, since $b_{k}($. is increasing in bidders' values, this necessary condition is also sufficient. For $r_{k} \leq y_{k-1}$, it thus follows that

$$
-\partial_{r_{k}} b_{k}\left(r_{k}, y_{1}, . ., y_{k-1}\right) F\left(r_{k}\right)^{n-k}+\left.\left[x-b_{k}\left(r_{k}, y_{1}, . ., y_{k-1}\right)\right](n-k) F\left(r_{k}\right)^{n-k-1} f\left(r_{k}\right)\right|_{r_{k}=x}=0
$$

which yields

$$
\partial_{r_{k}} b_{k}\left(x, y_{1}, . ., y_{k-1}\right)= \begin{cases}{\left[x-b_{k}\left(x, y_{1}, . ., y_{k-1}\right)\right](n-k) \frac{f(x)}{F(x)},} & \text { if } x \leq y_{k-1} \\ 0, & \text { if } x>y_{k-1}\end{cases}
$$

This is a first-order differential equation which has for boundary condition $b(0,)=$.0 . Since $\partial_{r_{k}} b_{k}\left(x, y_{1}, \ldots, y_{k-1}\right)$ is independent of $y_{1}, \ldots, y_{k-1}$ for any $x \leq y_{k-1}, b_{k}\left(x, y_{1}, \ldots, y_{k-1}\right)=b_{k}(x)$. On the other hand, for $x>y_{k-1}, b_{k}\left(x, y_{1}, \ldots, y_{k-1}\right)=b_{k}\left(y_{k-1}\right)$. The last stage equilibrium bidding strategy is thus a function defined by $b_{k}\left(\min \left\{x, y_{k-1}\right\}\right)$.

For stages $t=1, \ldots, k-1$, the bidder's expected profit can be expressed as depending on his willingness to deviate from $b_{t}($.$) , given that in stage t+1$ he will bid in equilibrium. For the next-to-last stage, his expected profit takes the following expression

$$
\Pi_{k-1}\left(r_{k-1}, x, b\left(r_{k-1}\right)\right)= \begin{cases}\int_{0}^{\mathrm{r}_{\mathrm{k}-1}}\left[x-b_{k-1}\left(r_{k-1}, y_{1}, . ., y_{k-2}\right)\right] f_{Y_{k-1}}\left(\alpha \mid y_{k-2}\right) d \alpha \\ \quad+\delta \int_{r_{k-1}}^{y_{k-2}}\left[x-b_{k}(\min \{x, \alpha\})\right] f_{Y_{k-1}}\left(\alpha \mid y_{k-2}\right) d \alpha, & \text { if } r_{k-1} \leq y_{k-2} \\ {\left[x-b_{k-1}\left(r_{k-1}, y_{1}, . ., y_{k-2}\right)\right],} & \text { if } r_{k-1}>y_{k-2}\end{cases}
$$

If $r_{k-1} \leq y_{k-2}$, the second line represents the profit a bidder expects for the $k^{\text {th }}$ stage given that he did not win the previous auction (where he bid as if his value was $r_{k-1} \leq y_{k-2}$ ) and that he will 
use his optimal strategy in the $k^{\text {th }}$ auction. On the other hand, by bidding in the next-to-last stage as if his value was $r_{k-1}>y_{k-2}$, that bidder will win with probability one since the bidding strategies are assumed to be strictly increasing in bidders' values.

The maximization of the bidder's expected profit for the last stage requires that $\left.\partial_{r_{k-1}} \Pi_{k-1}\left(r_{k-1}, x, b\left(r_{k-1}\right)\right)\right|_{r_{k-1}=x}=0$. That is, for $r_{k-1} \leq y_{k-2}$

$$
\begin{aligned}
& -\partial_{r_{k-1}} b_{k-1}\left(r_{k-1}, y_{1}, . ., y_{k-2}\right) F\left(r_{k-1}\right)^{n-k+1} \\
& +\left[x-b_{k-1}\left(r_{k-1}, y_{1}, . ., y_{k-2}\right)\right](n-k+1) F\left(r_{k-1}\right)^{n-k} f\left(r_{k-1}\right) \\
& \quad-\left.\delta\left[x-b_{k}\left(\min \left\{x, r_{k-1}\right\}\right)\right](n-k+1) F\left(r_{k-1}\right)^{n-k} f\left(r_{k-1}\right)\right|_{r_{k-1}=x}=0
\end{aligned}
$$

The solution of this equation is different whether $x>r_{k-1}$ or $x<r_{k-1}$ but it converges to the same value as $r_{k-1}$ approaches $x$. By setting it equal to 0 at $x=r_{k-1}$, we obtain the following differential equation

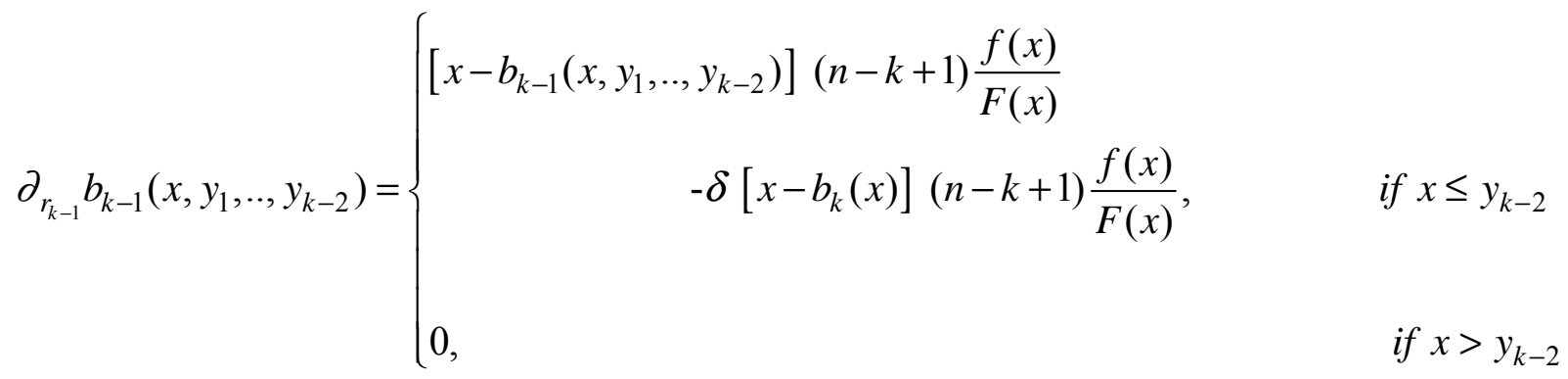

It follows that the equilibrium bidding strategy for the $(k-1)^{\text {th }}$ auction stage is independent of $y_{1}, \ldots, y_{k-2}$ if $x \leq y_{k-2}$, so that $b_{k-1}\left(x, y_{1}, \ldots, y_{k-2}\right)=b_{k-1}(x)$; and that $b_{k-1}\left(x, y_{1}, \ldots, y_{k-2}\right)=b_{k-1}\left(y_{k-2}\right)$ if $x>$ $y_{k-2}$. The equilibrium bidding function for the $(k-1)^{\text {th }}$ auction stage is thus again defined as $b_{k-}$ ${ }_{1}\left(\min \left\{x, y_{k-2}\right\}\right)$ and bids do not depend on past prices.

The same procedure is used to define the equilibrium bidding strategies for the $(k-2)$ remaining auction stages. At the outset of the sequence, $y_{0}$ is assumed to be equal to infinity (or to the maximum of the support of $F($.$) if its support has an upper-bound). The t^{\text {th }}$-stage optimal bidding strategy is then defined as $b_{t}\left(\min \left\{x, y_{t-1}\right\}\right)$. As the bidding strategies are monotone increasing in the buyer's valuation, the symmetric bidding strategy $b_{t}\left(\min \left\{x, y_{t-1}\right\}\right)$ is actually equal to $b_{t}(x)$ since $x \leq y_{t-1}$, for all $t$. Therefore, for the $k^{\text {th }}$ auction stage, the equilibrium strategy has the following expression 


$$
b_{k}(x)=x-\int_{0}^{x}\left[\frac{F(t)}{F(x)}\right]^{n-k} d t \equiv E\left\{X_{k+1} \mid X_{k}=x\right\}
$$

and for the next-to-last auction it has the following expression

$$
\begin{gathered}
b_{k-1}(x)=\delta \cdot\left\{(n-k+1)\left[x-\int_{0}^{x}\left[\frac{F(t)}{F(x)}\right]^{n-k} d t\right]-(n-k)\left[x-\int_{0}^{x}\left[\frac{F(t)}{F(x)}\right]^{n-k+1} d t\right]\right\} \\
+(1-\delta)\left\{x-\int_{0}^{x}\left[\frac{F(t)}{F(x)}\right]^{n-k} d t\right\} \\
=\delta E\left\{X_{(k+1)} \mid X_{(k-1)}=x\right\}+(1-\delta) E\left\{X_{(k)} \mid X_{(k-1)}=x\right\}
\end{gathered}
$$

$b_{k-2}, b_{k-3}, . ., b_{1}$ are recursively obtained in a similar way.

\section{Proof of Proposition 2:}

1. For $\delta=1, b_{k-l}(x)=E\left\{X_{(k+1)} \mid X_{(k-l)}=x\right\}$

$$
\begin{aligned}
& \left.E\left\{b_{k-l}\left(X_{(k-l)}\right) \mid b_{k-l-1}\left(X_{(k-l-1)}\right)=\beta\right\} \Leftrightarrow E\left\{E\left\{X_{(k+1)} \mid X_{(k-l)}\right)\right\} \mid b_{k-l-1}^{-1}(\beta)=X_{(k-l-1)}\right\} \\
& \Leftrightarrow E\left\{X_{(k+1)} \mid b_{k-l-1}^{-1}(\beta)=X_{(k-l-1)}\right\} \Leftrightarrow b_{k-l-1}\left(b_{k-l-1}^{-1}(\beta)\right)=\beta
\end{aligned}
$$

2. For $0<\delta<1$, take the difference between the expected price of the $(k-l)^{\text {th }}$ stage (i.e., the unconditional expected winning bid) obtained when $\delta \in(0,1)$ with the one obtained when $\delta=1$. That is,

$$
\left(\delta^{l} E\left\{X_{(k+1)}\right\}+\sum_{i=0}^{l-1} \delta^{i}(1-\delta) E\left\{X_{(k-l+i+1)}\right\}\right)-E\left\{X_{(k+1)}\right\}
$$

or equivalently,

$$
(1-\delta) \sum_{i=0}^{l} \delta^{i}\left[E\left\{X_{(k-l+i+1)}\right\}-E\left\{X_{(k+1)}\right\}\right]
$$

which is positive for any $0<l<k-1$, and increasing with $l$ for any $\delta \in(0,1)$. For $l=0$, this expression is equal to zero. By differentiating it with respect to $\delta$, it follows that its sign would always be negative for $\delta>0$. 


\title{
Appendix 2: (Translated) Instructions (0.6-treatment)
}

\author{
Outline of the experiment
}

1. In the experiment, each of you will participate in 100 auction rounds.

2. In each round, up to 4 identical items are sold and you compete with 7 other participants to buy one of those. Since there are 8 participants in the auction and since there are at most 4 items to be sold, at least 4 of the 8 participants will not get an item in a given round.

3. You will compete with the same 7 other participants during the 100 rounds.

4. The items are sold sequentially, one after the other, in up to 4 stages. Once the first item is sold, a "Wheel of Fortune" is run. The possible outcomes are Green with a probability of $60 \%$ and Red with a probability of $40 \%$. If the outcome is Green, the next stage will take place. Otherwise, the current round ends instantaneously, and the next round takes place.

4. Your objective in a given round is to submit bids to get an item. A bid consists in proposing a price of purchase.

5. In each auction, the participant who submitted the highest bid is awarded the item for a price which is equal to his/her bid.

6. When an item has been awarded to you, you will not be allowed to submit any further bid in that round. You will have to wait for the next round, because you can only buy one item a round.

7. If in any stage of an auction, two or more participants submit the same highest bid, then the winner will be randomly chosen among them (with equal probability).

\section{The Gains}

8. At the outset of each round, each of you will receive a number that is randomly drawn between 0 and 100 (any number has the same probability of being drawn). This number represents the value that you assign to any of the items sold in that round.

9. You know your value, but you do not know the values of the other participants.

10. Your bid may be any number between 0 and 100. If nobody submits a bid greater than 0 in a given stage of a round then the round will be cancelled.

11. If you win and your bid is smaller than your value then you will make a gain that is equal to the difference between your value and your bid (i.e., the price you pay).

12. If you win and your bid is equal to your value then you will make no gain.

13. If you win and your bid is greater than your value, then you make a loss that is equal to the difference between your value and your bid (i.e., the price you pay).

14. If you do not win, then you make no gain.

15. The payoff from participating in this experiment will be equal to the sum of all your gains.

16. Values, bids, prices, gains and payoffs in this experiment refer to Coronas. The exchange rate is 1 Corona for 5 Ptas. The payoff you made will be anonymously paid to you at the end of the experiment.

\section{The menu}

17. At any time during the experiment, you can check your past values, the prices at which previous items were sold and the gains you made by looking at the History window, press key "H".

18. If you want to use the calculator of the program, press key "A". 


\section{Appendix 3: Estimated Four-Piecewise Linear (Spline) Bid Functions}

Treatment: $\delta 0.6$

Group 1

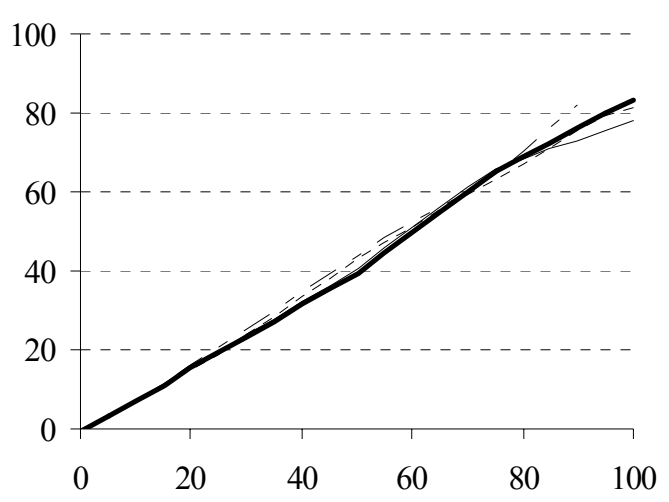

Group 3

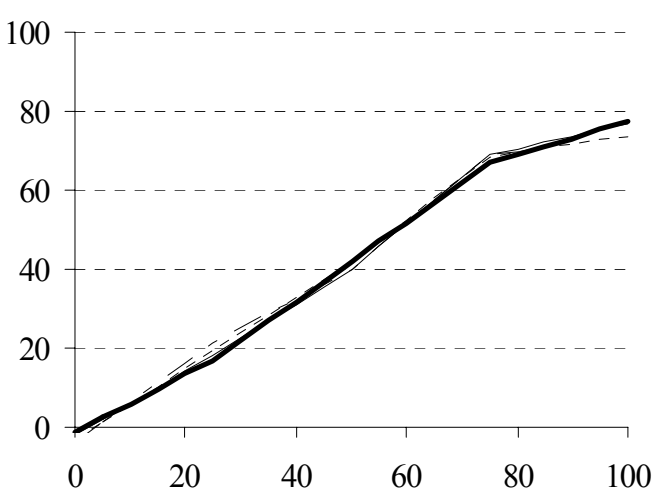

Group 5

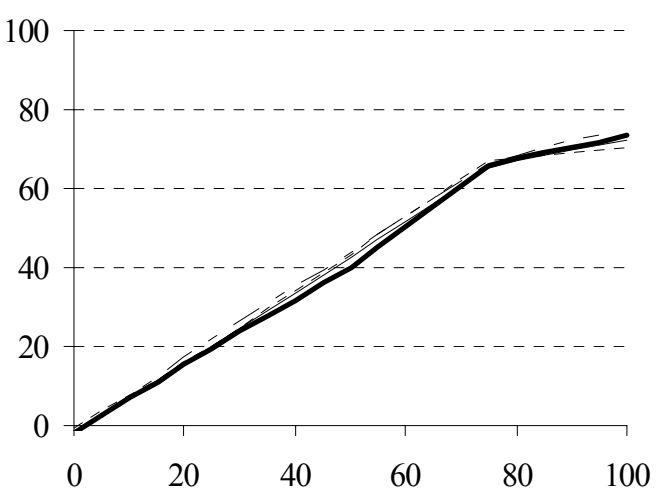

Group 2

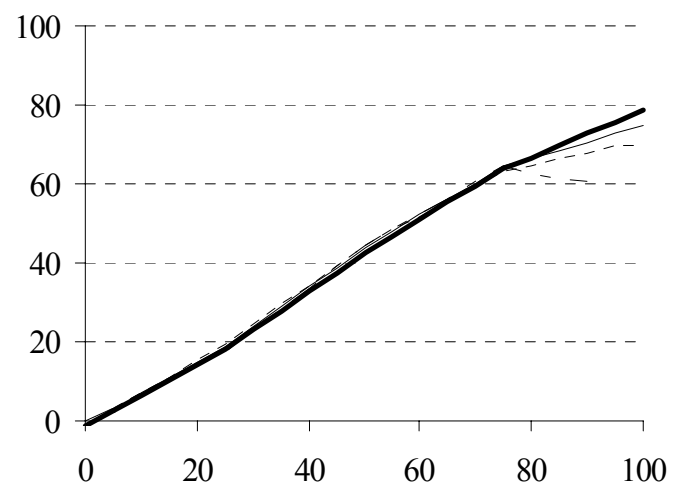

Group 4

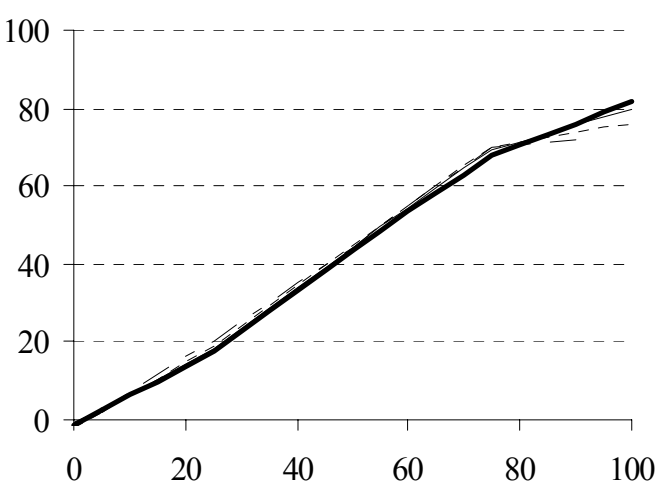

Group 6

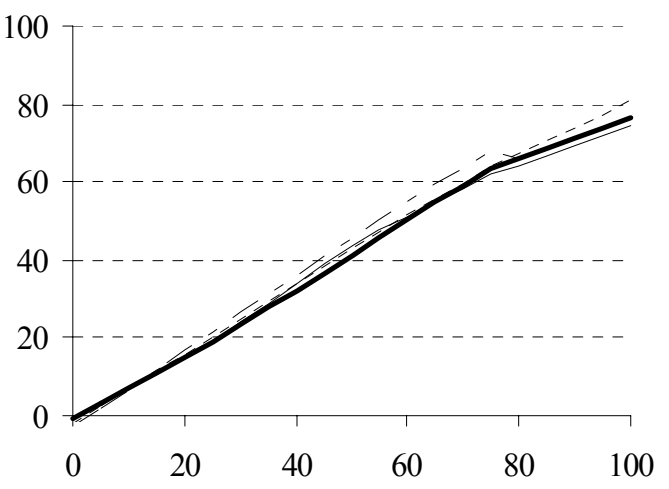

Average

$\%$ (bids) for values $>75$

25.5

17.1

9.6

4 


\section{Treatment: $\boldsymbol{\delta 0 . 8}$}

Group 1

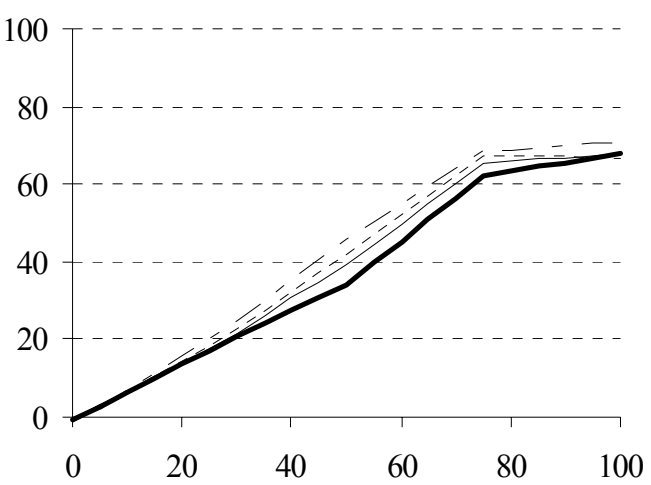

Group 3

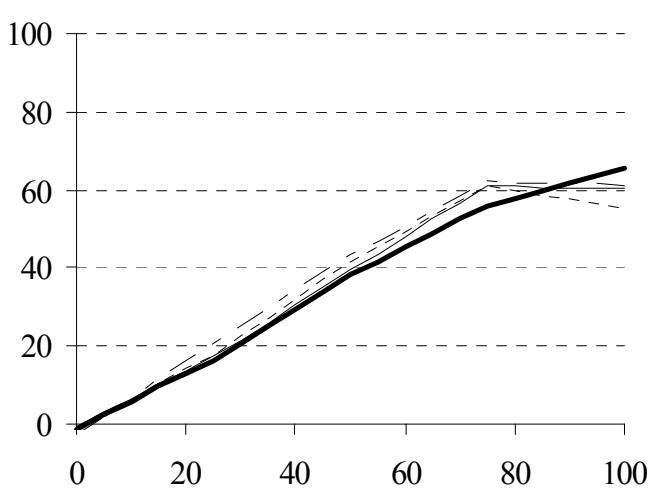

Group 5

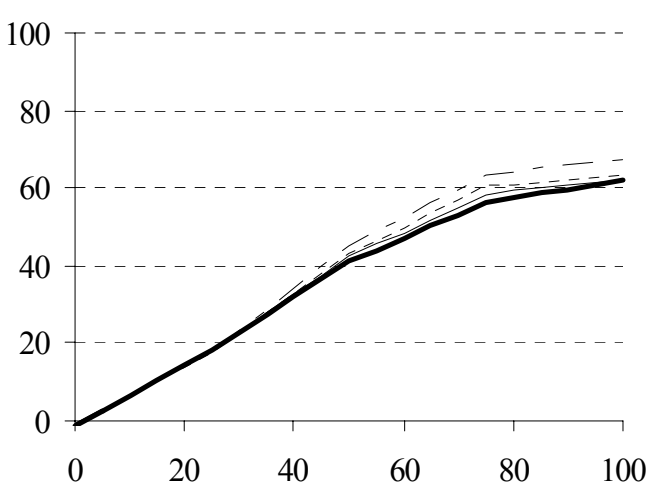

Group 2

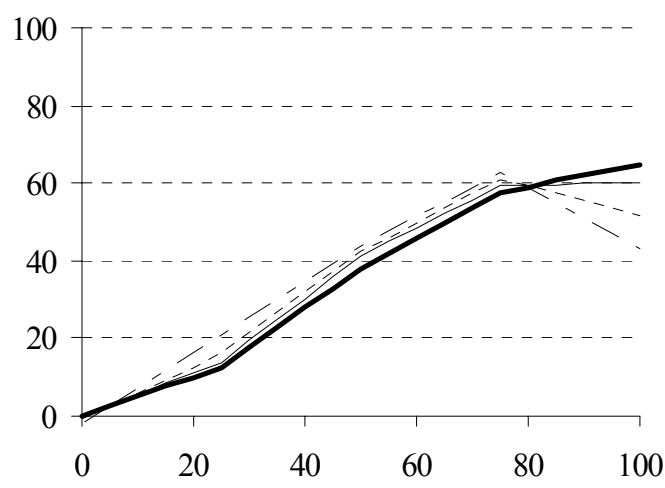

Group 4

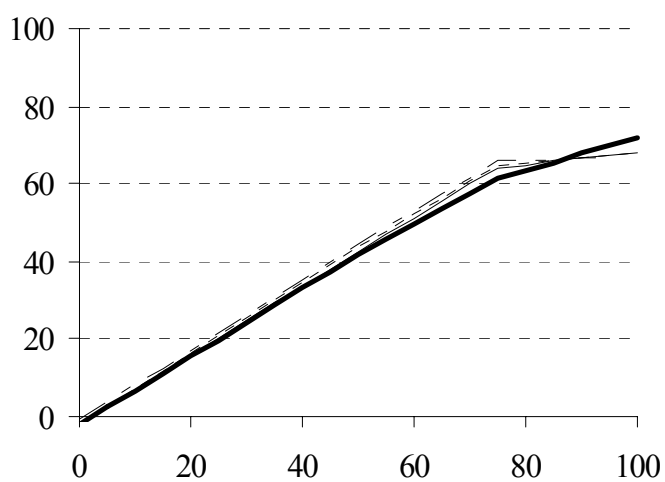

Group 6

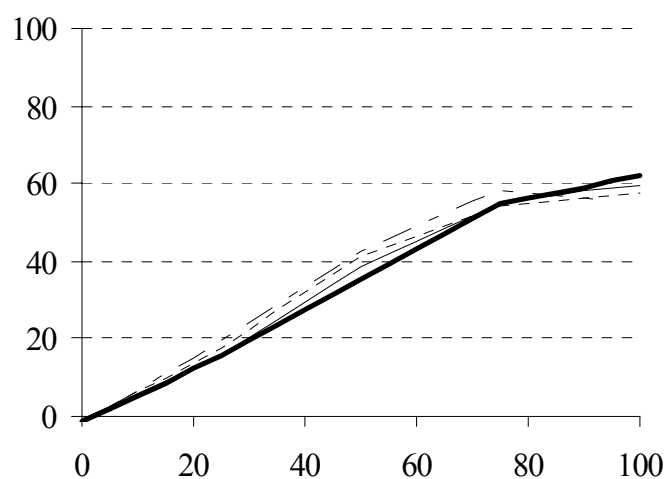

Average

$\%$ (bids) for values $>75$

\begin{tabular}{|c|c|c|}
\hline Legend: & & Stage 1 \\
\hline & & Stage 2 \\
\hline & ---- & Stage 3 \\
\hline & $-\cdots-\cdots$ & Stage 4 \\
\hline
\end{tabular}


Treatment: $\delta 1.0$

Group 1

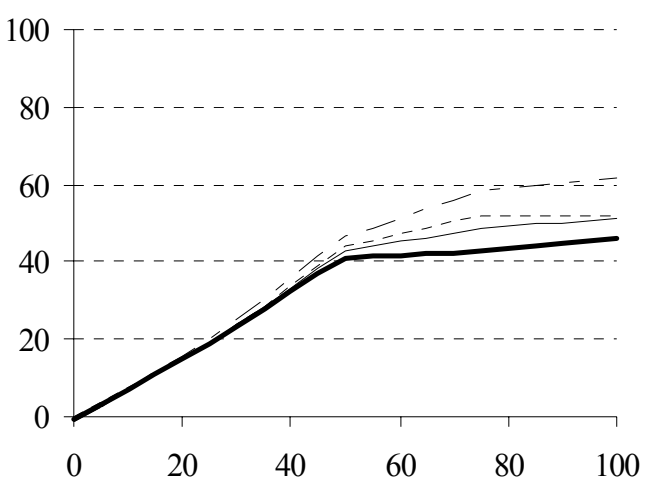

Group 3

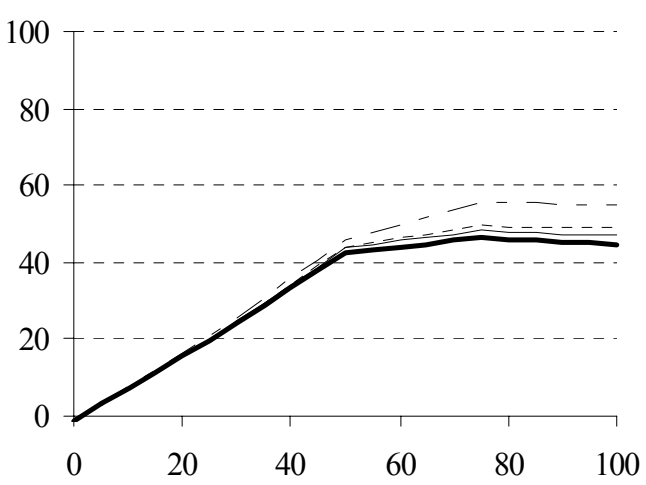

Group 5

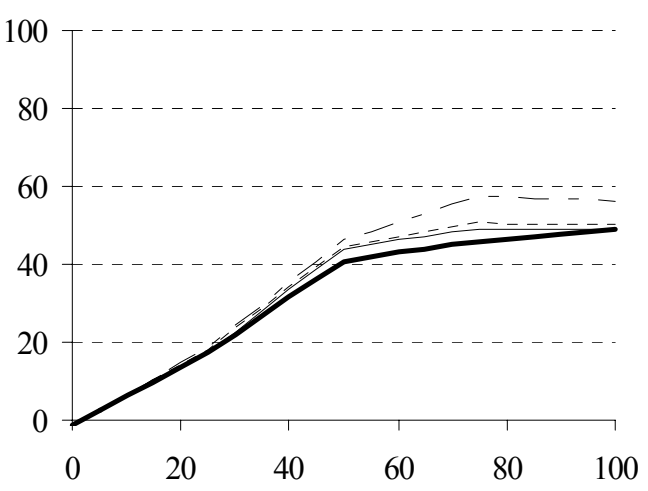

Group 2

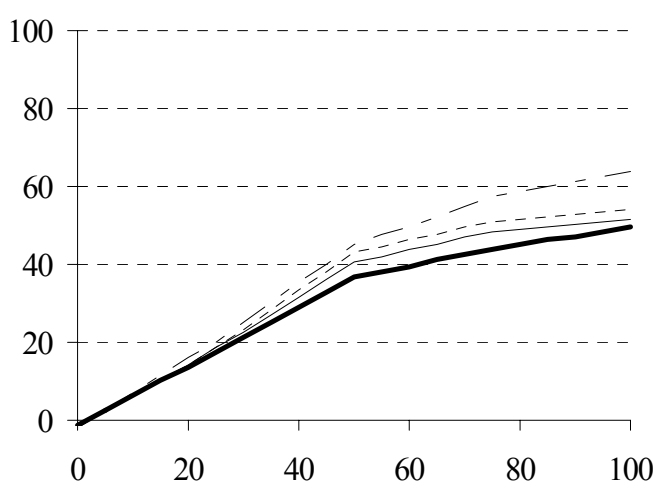

Group 4

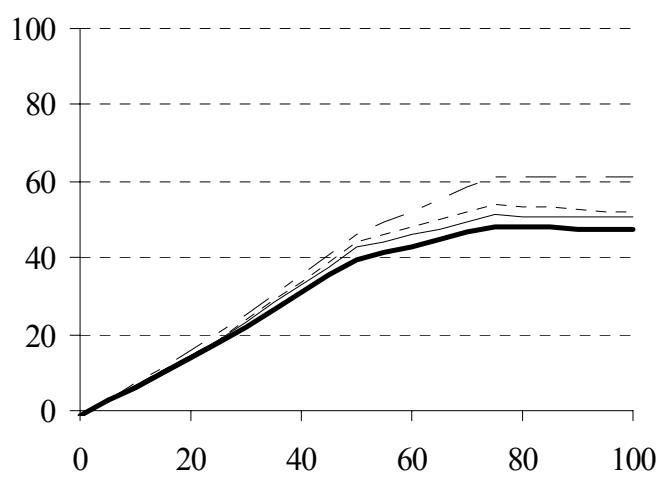

Group 6

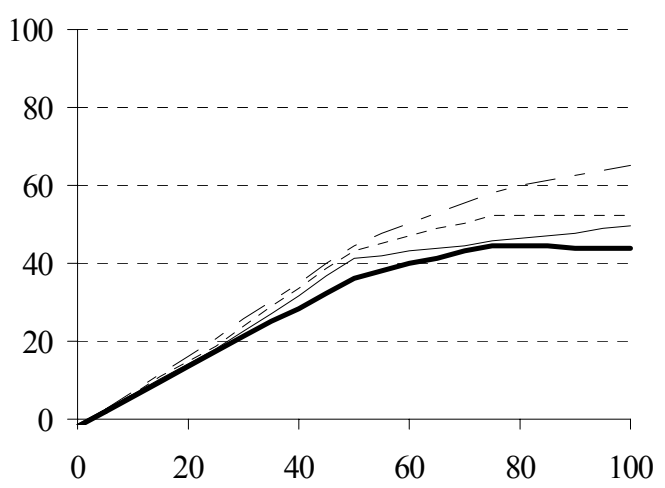

Average

$\%$ (bids) for values $>75$

$\begin{array}{lllr}\text { Legend: } & \longrightarrow & \text { Stage 1 } & 25.3 \\ & & \text { Stage 2 } & 21 \\ & ---- & \text { Stage 3 } & 15 \\ & -\cdots-\cdots & \text { Stage 4 } & 9.3\end{array}$




\section{Appendix 4}

Table A: Average Differences in Stage-to-Stage Bid-to-Value Ratios of Low and High Value bidders

\begin{tabular}{|c|c|c|c|c|c|c|c|c|}
\hline \multicolumn{3}{|c|}{ Treatment 80.6} & \multicolumn{3}{|c|}{ Treatment 80.8} & \multicolumn{3}{|c|}{ Treatment $\delta 1.0$} \\
\hline $\mathrm{D}_{1}$ & $\mathrm{D}_{2}$ & $\mathrm{D}_{3}$ & $\mathrm{D}_{1}$ & $\mathrm{D}_{2}$ & $\mathrm{D}_{3}$ & $\mathrm{D}_{1}$ & $\mathrm{D}_{2}$ & $\mathrm{D}_{3}$ \\
\hline .001 & .010 & -.010 & -.014 & -.001 & .001 & -.027 & -.034 & -.054 \\
\hline 1.00 & .219 & .844 & .156 & .438 & .438 & .031 & .031 & .031 \\
\hline
\end{tabular}

